\title{
Reducing magnetic field induced noise in broad-band seismic recordings
}

\author{
Thomas Forbriger* \\ Black Forest Observatory (BFO), Research Facility of the Universities of Karlsruhe and Stuttgart, Heubach 206, D-77709 Wolfach, Germany. \\ E-mail: Thomas.forbriger@gpi.uni-karlsruhe.de
}

Accepted 2006 November 13. Received 2006 October 26; in original form 2006 April 18

\begin{abstract}
SUMMAR Y
Seismic broad-band sensors are known to be sensitive to the magnetic field. Magnetic storms and man-made disturbances of the magnetic field can produce significant noise in seismic recordings. I show that variations in the magnetic field translate directly into apparent acceleration of the seismic sensor within the period range from 60 to $1200 \mathrm{~s}$ for all leaf-spring sensors under investigation. For a Streckeisen STS-1V this is shown even for periods down to $1 \mathrm{~s}$. The sensitivity is quantified in magnitude and direction. Both are quite stable over many time windows and signal periods. The sensitivities obtained by linear regression of the acceleration signal on magnetic field recordings during a magnetic storm can effectively be applied to reduce noise in seismic signals. The sensitivity varies in magnitude from sensor to sensor but all are in the range from 0.05 to $1.2 \mathrm{~m} \mathrm{~s}^{-2} \mathrm{~T}^{-1}$. Seismograms from sensors at Black Forest Observatory (BFO) and stations of the German Regional Seismic Network were investigated. Although these are mainly equipped with leaf-spring sensors, the problem is not limited to this type of instrument. The effect is not observable on the horizontal component STS-1s at BFO while it is significant in the recordings of the vertical STS- 1 . The main difference between these instruments is the leaf-spring suspension in the vertical component that appears to be the source of the trouble. The suspension springs are made of temperature compensated Elinvar alloys that inherently are ferromagnetic and may respond to the magnetic field in various ways. However, the LaCoste Romberg ET-19 gravimeter at BFO, which uses this material too, does not respond to magnetic storms at a similar magnitude neither do the Invar-wire strainmeters. An active shielding, composed of three Helmholtz coils and a feedback system, is installed at station Stuttgart and provides an improvement of signal-to-noise ratio by almost a factor of 20 at this particular station. The passive Permalloy shielding commonly installed with STS-1V sensors performs similarly well.
\end{abstract}

Key words: broad-band seismometers, instrumental noise, magnetic field.

\section{OBJECTIVE}

Many seismometers and gravimeters are sensitive to the magnetic field (Torge 1989; Klinge et al. 2002; Wielandt 2002b; Pálinkás et al. 2003). A magnetic storm on 2001 March 31 that was clearly observed in the routine simulation of a long-period World Wide Standardised Seismograph Network (WWSSN) recording from the Streckeisen STS-2 at station Taunus (TNS) in the German Regional Seismic Network (GRSN) motivated me to study this effect in detail. I use observations from magnetic storms and man-made variations of the magnetic field to study the nature and source of the sensitivity of broad-band seismometers to the magnetic field.

\footnotetext{
*Also at: Geophysical Institute, University of Karlsruhe, Hertzstraße 16, D-76187 Karlsruhe, Germany.
}

First, I will give three examples of natural and artificial causes of magnetic field noise on seismic recordings to demonstrate their significance. In Section 3, the transfer function between magnetic field recordings and noise on seismic recordings is derived from the observation of a magnetic storm for Streckeisen STS-1 and STS-2 seismometers (see Table 1 for properties of instruments). Finally, I discuss possible transfer mechanisms in Section 4 and potential counter-measures in Section 5.

\section{OBSERVATIONS}

\subsection{Magnetic storms}

Figs 1 and 2 show the response of GRSN stations (Fig. 3 and Table 2) to the magnetic storms on 2001 March 31 and 2003 October 29. The noise-level at almost all stations rises with the sudden storm 
Table 1. Instruments used in this study.

STS-1: The STS-1 broad-band seismometer was developed by Wielandt \& Streckeisen (1982). Its vertical component sensor uses a leaf-spring suspension (Wielandt 1975). The approximate geometry of the leaf-spring and the pendulum is sketched by Wielandt (2002a, Fig. 5.10; 2002b, Fig. 4) and is reproduced by Aki \& Richards (2002, Fig. 12.23) from Wielandt \& Streckeisen (1982). The instrument (serial number 1828) used in Section 5.1 is an early STS-1V vertical component sensor with 20 s eigenperiod of the feedback system. The later VBB-version (very broad-band) uses the same mechanical sensor (Wielandt \& Steim 1986) but a feedback for an eigenperiod of $360 \mathrm{~s}$. The leaf-spring in the vertical component sensor is made from an Elinvar alloy which is known to be ferromagnetic. All components use springs in the hinges that are known to be magnetic. Some of the stainless steel skrews that are used in the pendulum show a slight magnetism. Further a small pin made from ferrite in the displacement transducer is attached to the pendulum. All other components are not known to be ferromagnetic (they are made from aluminium, brass, etc.). The vertical component instruments are commonly deployed inside a Permalloy shielding against the influence of variations of the magnetic field. A set with a vertical component (serial number 28740, protected by a Permalloy casing) and two horizontal components (serial numbers: $18784 \mathrm{~N}$-component, $18783 \mathrm{E}$-component) is installed at BFO. Their response to a magnetic storm is shown in Fig. 5.

STS-2: This is the Streckeisen STS-2 broad-band seismometer with 120 s eigenperiod. It contains a homogeneous triaxial arrangement of three identical sensors that use a leaf-spring suspension. The STS-2 has a capacitive displacement transducer and thus has no ferrite pin at the pendulum. Comments made for the Elinvar leaf-spring, the hinges, and the skrews in the STS-1 apply also for the STS-2. The instrument is described by Wielandt \& Widmer-Schnidrig (2002) and Wielandt (2002a, section 5.3.6 and Fig. 5.10 right; 2002b, section 18.2.7 and Fig. 4 right). The STS-2 with serial number 19123 is installed at BFO as part of the GRSN.

ET-19: This is the LaCoste Romberg earth tide gravimeter with serial number 19. It is installed at BFO. Richter et al. (1995) studied its performance. The LaCoste Romberg gravimeters use a suspension coil spring made from an Elinvar alloy. These springs are expected to be demagnetized prior to assembling the instrument. However, the instruments are known to be sensitive to the magnetic field, although at a lower level than the seismometers.

KS-36000: The Teledyne Geotech KS-36000 is a three component broad-band borehole seismometer with 360 s eigenperiod. The instrument uses a coil spring suspension for its vertical component. It uses a proprietary material (not further specified, presumably an Elinvar alloy) for the spring that is insensitive to temperature variations (Oncescu, personal communication 2006). The tubes are made from (ferromagnetic) carbon steel. The instrument installed at GRFO has serial number 015. It was built by Geotech Instruments, LLC, Dallas, USA.

KS-54000: Successor of the Teledyne Geotech KS-36000. According to Oncescu (Geotech Instruments, pers. comm. 2006) the mechanical sensor of both instruments is virtually identical. The main difference is the packaging of the electronics.

Invar-wire strainmeters: The Invar-wire strainmeters at BFO are a slightly modified version of the instruments described by King \& Bilham (1976) and Agnew (1986, section 5.2). The array at BFO is described by Widmer et al. (1992). The serial numbers and azimuths for the instruments from which the signals in Fig. 5 were obtained are: VSA: instrument St-0 (N2 ${ }^{\circ}$ E), VSB: instrument St-4 (N60 ${ }^{\circ}$ E), and VSC: instrument St-3 (N300 $\left.{ }^{\circ}\right)$. A $10 \mathrm{~m}$ long wire made from an Invar alloy is the key part of the sensor. Invar is inherently ferromagnetic.

Askania tiltmeter: This vertical pendulum tiltmeter currently operated at BFO was manufactured by the Askania company and has the serial number 10. It is described by Agnew (1986, section 4.1.6 and Fig. 15). Mälzer et al. (1979) give a description of the installation at BFO. Since 1996 the instrument at BFO uses the lock-in amplifier of an STS-1 for its displacement transducers. The Askania pendulum is not known to contain any parts of significant magnetic permeability attached to its pendulum. Like the KS-36000 the Askania pendulum is deployed in tubes made from ordinary, ferromagnetic steel.

Rasmussen fluxgate: This is a fluxgate magnetometer model FGE obtained from the Danish Meteorological Institute. It was was developped by Rasmussen (1997). The instrument installed at BFO has the serial number S0230. The three components of this magnetometer are in operation since 2002. The data is published through Intermagnet (http://www.intermagnet.org/) since 2006.

GSM-90: This is an Overhauser proton magnetometer built by GEM Systems, Richmond Hill, Canada. The data is published through Intermagnet (http://www.intermagnet.org/) since 2006.

commencement (SSC). Only station Stuttgart (STU), which is protected by active shielding (see below), does not respond to the SSC. In the case of station TNS the magnetic signal was easily observed in the simulation of a long-period WWSSN system that is routinely produced at the Institute of Geophysics at the Johann WolfgangGoethe University at Frankfurt (Germany) for the purpose of quality control. The reader is invited to check this himself for both dates in long-period simulations of Seismic Research Observatory (SRO) recordings provided online ${ }^{1}$ by the Seismological Central Observatory (SZGRF) at Erlangen. The waveform of the signal that is induced by the magnetic field is similar for all stations. However, magnitude and sign are varying over the network. All stations of the GRSN are equipped with Streckeisen STS-2 seismometers (Table 1) whereas a Teledyne Geotech KS-36000 borehole instrument is installed at the IRIS station GRFO. Since the KS-36000 has a coil spring and responds to the SSC too, the effect is not limited to leaf-spring sensors.

\footnotetext{
${ }^{1}$ http://www.szgrf.bgr.de/dayplot.html
}

In a similar way the 'Harvard Seismology Real Time Noise' page ${ }^{2}$ by Göran Ekström reported a sudden increase of noise in the whole Global Seismic Network (GSN) at 6:12 UT on 2003 October 29 in response to the SSC (Fig. 4). Visually selecting the traces responding strongest and those responding weakest to the SSC, I find that the effect appears to be more significant at high latitudes (Table 3). Streckeisen STS-1 seismometers and Geotech KS-54000 are affected as well.

Checking all seismic sensors at the Black Forest Observatory (BFO) I find only the STS-2 (GRSN seismometer) and the vertical component STS-1 responding to the magnetic storm (Fig. 5). This may be surprising since the ferromagnetic properties of Invar and Elinvar alloys used in the suspension springs are suspected to be the source of the trouble as will be discussed below. However, neither the LaCoste Romberg ET-19 gravimeter, which uses an Elinvar suspension spring, nor the Invar-wire strainmeters appear to be

\footnotetext{
${ }^{2}$ http://www.seismology.harvard.edu/ ekstrom/Research/Noise/RADB_ hourly_rms.html
} 

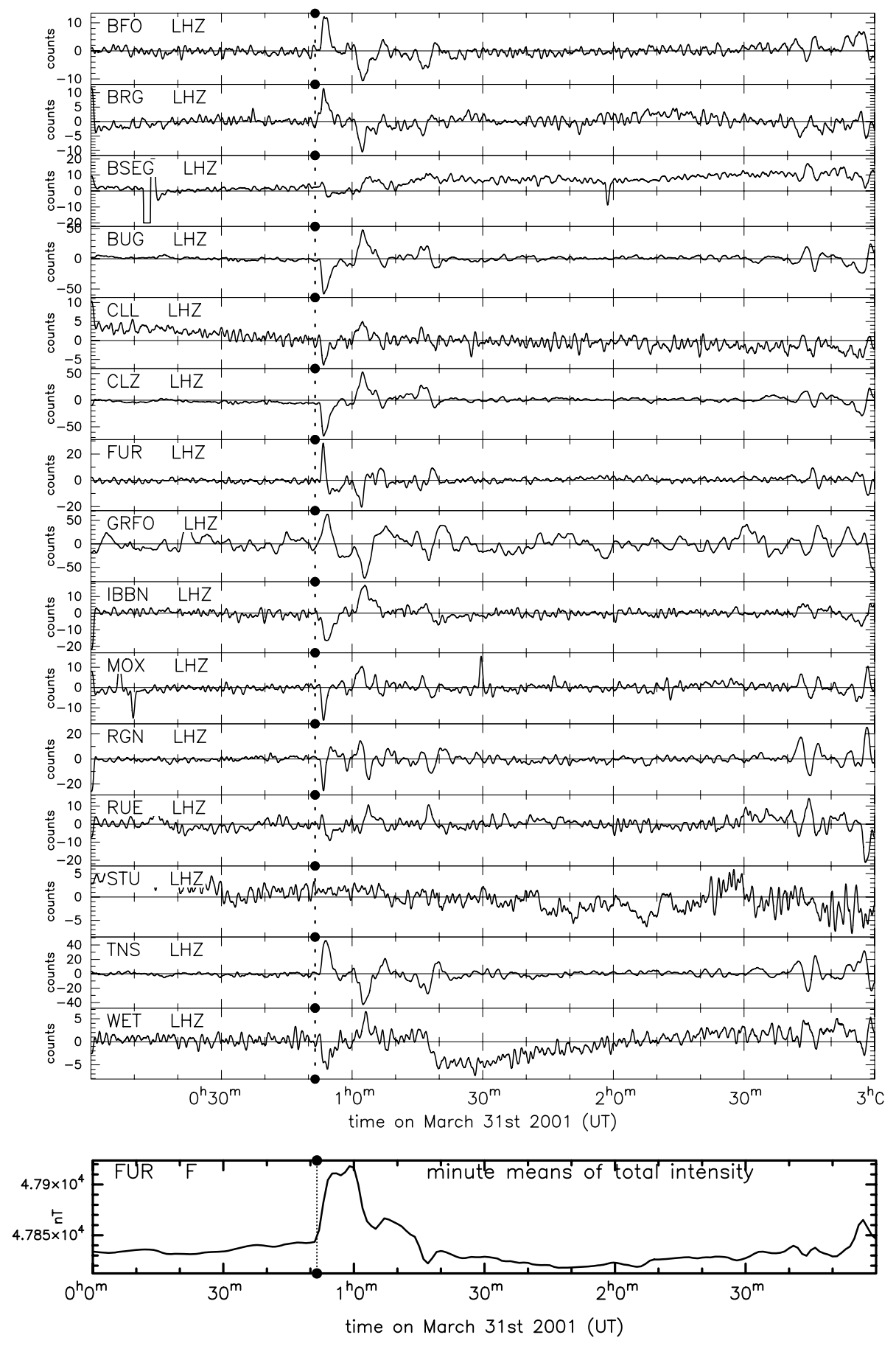

Figure 1. Vertical component data for stations of the German Regional Seismic Network (GRSN) and the Incorporated Research Institutions for Seismology (IRIS) station GRFO (Fig. 3, Table 2). Almost all stations respond immediately to the SSC (sudden storm commencement) on 2001 March 31 00:51:30 UT with an increased noise level. The SSC is obvious in the recording of the total magnetic intensity recorded at FUR and shown in the bottom panel. All seismic stations except GRFO are equipped with STS-2 seismometers (Table 1). GRFO which is equipped with a KS-36000 borehole instrument responds to the magnetic storm too. BSEG and MOX had additional problems. A spike in the BSEG record was clipped intentionally before plotting. The only station not obviously responding (notice the vertical scale) is STU which is protected by an active shield. The raw time-series were lowpass filtered with a $60 \mathrm{~s}$ Butterworth filter of fourth-order to remove microseisms.

sensitive at a magnitude comparable to the seismometers. This is in agreement with the observations by Pálinkás et al. (2003) who found a maximum sensitivity of $0.008 \mathrm{~m} \mathrm{~s}^{-2} \mathrm{~T}^{-1}$ for the LaCoste Romberg LCR G No.137 gravimeter which is by a factor 10-100 smaller than the sensitivities found for leaf-spring seismometers.
Further they report no common relation between the direction of sensitivity and the internal geometry of the sensor. This is different for leaf-spring seismometers where I observe a sensitivity predominantly perpendicular to the mechanical axis of the pendulum as is shown below. 

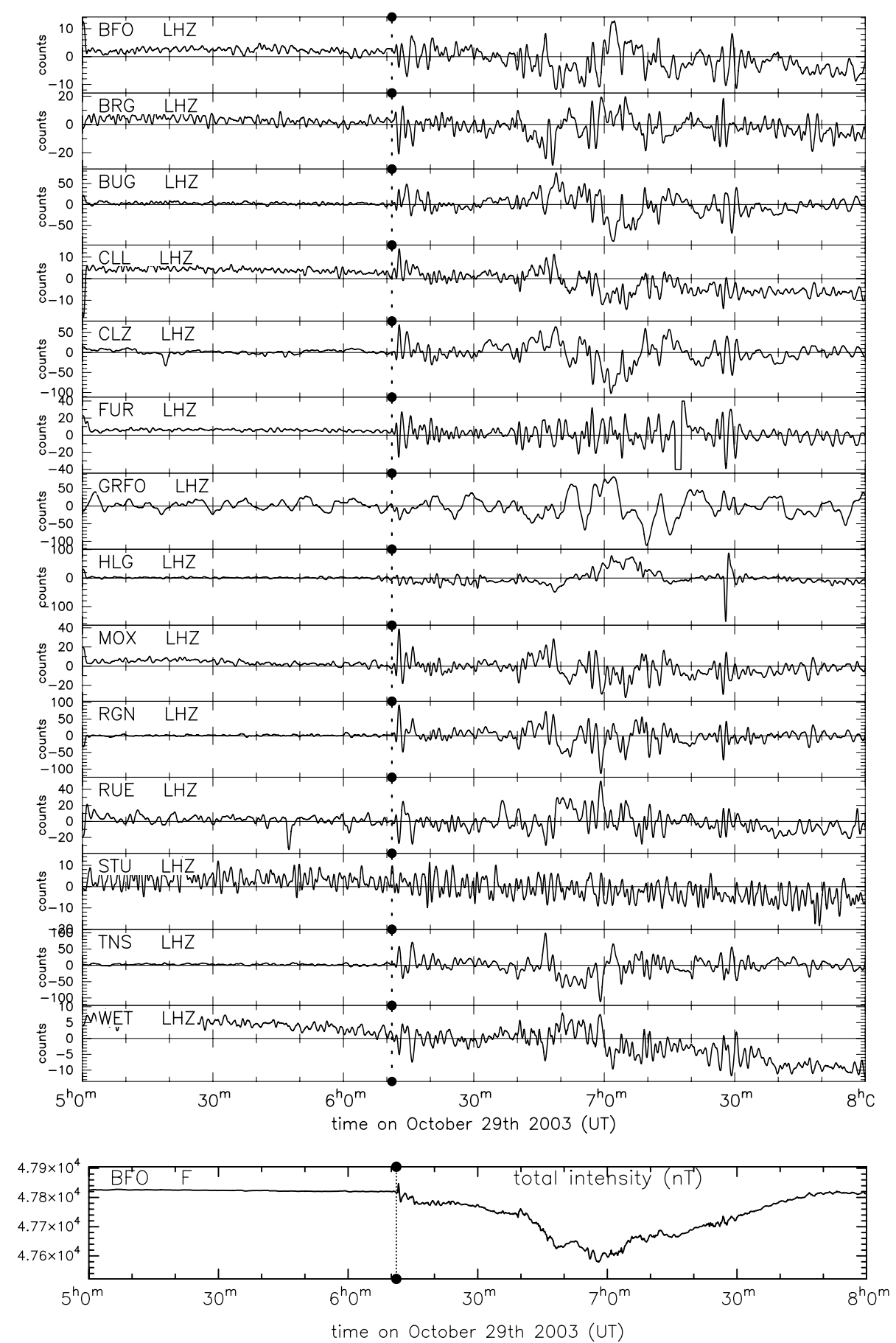

Figure 2. Vertical component data for GRSN stations and the IRIS station GRFO (Fig. 3, Table 2). Almost all stations respond immediately to the SSC (sudden storm commencement) on 2003 October 29 06:11:10 UT with an increased noise level. The SSC is obvious in the recording of the total magnetic intensity recorded with the GSM-90 (Table 1) at BFO and shown in the bottom panel. Like in Fig. 1 GRFO responds too, while STU does not. See there for filter parameters. FUR and HLG suffered from additional problems. A spike in the FUR record was clipped intentionally before plotting.

\subsection{Man-made noise}

Apart from natural sources (magnetic storms) man-made variations of the magnetic field can be strong enough to be a significant source of noise. One of the most prominent examples is station STU. The station's pier is located in a former air-raid shelter at $20 \mathrm{~m}$ below the surface on hard triassic marls in the city of Stuttgart
(Fig. 3 and Table 2). While the long period horizontal components are significantly disturbed by tilts due to cars passing above, the vertical component's signal can easily compete with that of other GRSN stations. However, this data quality was only achieved by the thermal and air-pressure protection that is common in the GRSN (Wielandt \& Widmer-Schnidrig 2002) together with additional magnetic shielding. The shield consists of a three component 


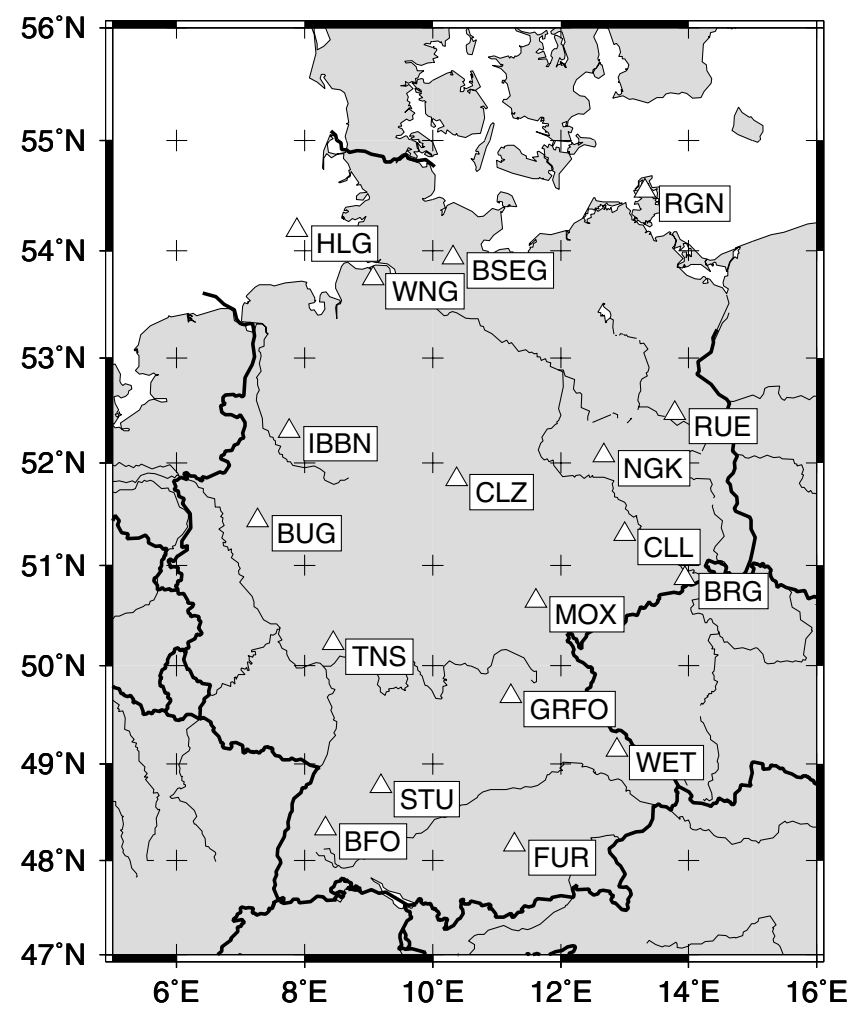

Figure 3. Seismic stations and geomagnetic observatories referred to in this study. The names of the stations and their relation to seismic networks are given in Table 2. Wingst (WNG) and Niemegk (NGK) are geomagnetic observatories operated by the GeoForschungsZentrum (Potsdam, Germany). Fürstenfeldbruck (FUR) is operated by the Ludwig Maximilians University (Munich, Germany) and hosts the station FUR of the German Regional Seismic Network (GRSN) in addition to a geomagnetic observatory. Black Forest Observatory (BFO) is a research facility of the Universities of Karlsruhe and Stuttgart. Among several seismic sensors it operates geomagnetic sensors and hosts station BFO of the GRSN. Data from the magnetic observatories can be obtained through Intermagnet (www.intermagnet.org). This map was prepared with GMT (Wessel \& Smith 1995).

fluxgate sensor, an electronic feedback driver circuit, and a cube ${ }^{3}$ of three Helmholtz coils to compensate variations of the magnetic field (Wielandt 2002a, section 5.5.4; 2002b, section 18.6.4). The latter are caused by fluctuating electric currents in the ground. The electric streetcars in the city return their current through the rails. However, over distances of several kilometres most of the current flows through the subsoil and induces significant variations of the magnetic field there. The active shield is essential to eliminate these variations. Fig. 6 shows the effect of a temporary breakdown of the shielding. In consequence the signal quality severely deteriorated. Station BRNL in Berlin-Lankwitz suffered from the same source of noise until it was moved to RUE in 2000 (Walter Zürn, personal communication, 2005).

In 2001 November construction work was going on at a site close to station TNS (Table 2 and Fig. 3). Many heavy lorries passed the station in a distance of less than $10 \mathrm{~m}$. This is a very unusual situation for TNS. The lorries could easily be identified by the tilt signals in the horizontal components that track the passing vehicles and clearly scale in amplitude with their load (Figs 7 and 8). Transient signals

\footnotetext{
${ }^{3}$ Visit http://www.geophys.uni-stuttgart.de/stu/gallery/Hstu.html to see a picture of the active magnetic shield at station STU.
}

in the vertical component (Fig. 7, top) that coincide with the tilts can only be explained by a disturbance of the magnetic field of $30 \mathrm{nT}$ which is a reasonable magnitude at a distance of $10 \mathrm{~m}$ to a lorry. Inertial acceleration due to vertical displacement caused by elastic loading can be ruled out due to the waveform of the signal. Other effects like gravity reduction due to hydraulic uplift (vertical movement of the ground due to variations in pore pressure as a result of the loading), buoyancy, tilt effect of second order and pure gravitational attraction can be ruled out too. They cannot reach the required order of magnitude. More importantly, all of them must scale with the surface load like the amplitude of the tilt signal does and which the vertical signal obviously does not (Fig. 7).

\section{TRANSFER FUNCTION}

I suggest that variations in the magnetic field directly translate into acceleration in the seismic recordings. This is reasonable because all effects that have an impact on the seismometer (like inertial acceleration, buoyancy, gravity, thermal expansion, etc.) are sensed through a residual acceleration acting on the sensor's pendulum in first place (Zürn \& Wielandt 2006). Nevertheless, this simple relation may be obscured by a more complicated transfer through the seismometer's casing like it is the case for variations of air pressure that cause buoyancy.

In the following, I will corroborate the hypothesis by predicting the magnetically induced signal on seismic recordings from independent recordings of the magnetic field. For this purpose, I use recordings from the Rasmussen fluxgate sensors installed at BFO since 2002 (Table 1). They provide the variations of three components of the magnetic field with a sampling interval of $1 \mathrm{~s}$. The $z$-component is aligned vertically and points downward. The $x$ - and $y$-components are not aligned to the north and east. They are off by an angle of $\varphi=26.44^{\circ}$. This orientation ensures significant contributions of the daily variation on all components. Components are rotated numerically to north and east before publication of the data through Intermagnet. However, in this study I use the original data. This must be kept in mind when using the sensitivities given below. The equation

$\vec{B}_{Z N E}=\left(\begin{array}{c}B_{Z} \\ B_{N} \\ B_{E}\end{array}\right)=\left(\begin{array}{ccc}0 & 0 & -1 \\ \cos \varphi & \sin \varphi & 0 \\ -\sin \varphi & \cos \varphi & 0\end{array}\right)\left(\begin{array}{l}B_{x} \\ B_{y} \\ B_{z}\end{array}\right)=\mathbf{D} \vec{B}_{x y z}$

relates the fluxgate's $x$-, $y$ - and $z$-component to the components given in the usual seismic ZNE-reference frame.

\subsection{Linear regression}

As a test for the hypothesis given above, I use a linear regression of the magnetic field recordings on acceleration time-series obtained from the seismometers. I use recordings from the STS-1 and STS2 at BFO and from GRSN stations. Seismic and magnetic data is lowpass filtered with a fourth-order Butterworth filter at $60 \mathrm{~s}$ period. This removes microseisms and narrows the signal bandwidth to a period range where contributions by magnetic storms are expected. Seismic traces are deconvolved to acceleration. A second order Butterworth highpass at $1200 \mathrm{~s}$ period is applied to the magnetic field and the seismic recordings. Using larger periods, the deconvolution would become unstable. Recordings from 2003 October 29-31 are split into overlapping 2-hr windows. Within each window average and trend are removed from all signals. Then regression coefficients 
Table 2. Seismic stations used in this study. All stations except GRFO are part of the GRSN (German Regional Seismic Network, network code GR, Korn 2002) which is operated by the SZGRF (Seismological Central Observatory, Federal Institute for Geosciences and Natural Resources, Hannover, Germany). All are equipped with Streckeisen STS-2 seismometers. GRFO is a borehole station of the IRIS/USGS network (network code IU) and is equipped with a Teledyne Geotech KS-36000 borehole sensor (serial number 015). IRIS are the Incorporated Research Institutions for Seismology and the IU network is operated and maintained by the USGS Albuquerque Seismological Laboratory. GRSN stations with the network code GE are operated by GEOFON (GeoForschungsZentrum Potsdam, Germany). Local depth is given where provided by the network data centers. The location of these stations is displayed in Fig. 3.

\begin{tabular}{|c|c|c|c|c|c|c|}
\hline Station & Network & Station name & Latitude & Longitude & Elevation & Local depth \\
\hline $\mathrm{BFO}$ & GR & Black Forest Observatory & $48.3301^{\circ} \mathrm{N}$ & $8.3296^{\circ} \mathrm{E}$ & $589 \mathrm{~m}$ & $162 \mathrm{~m}$ \\
\hline BRG & GR & Berggießhübel & $50.8732^{\circ} \mathrm{N}$ & $13.9428^{\circ} \mathrm{E}$ & $296 \mathrm{~m}$ & $36 \mathrm{~m}$ \\
\hline BSEG & GR & Bad Segeberg & $53.9353^{\circ} \mathrm{N}$ & $10.3169^{\circ} \mathrm{E}$ & $40 \mathrm{~m}$ & \\
\hline BUG & GR & Bochum, Universität & $51.4406^{\circ} \mathrm{N}$ & $7.2693^{\circ} \mathrm{E}$ & $85 \mathrm{~m}$ & \\
\hline CLL & GR & Collm & $51.3077^{\circ} \mathrm{N}$ & $13.0026^{\circ} \mathrm{E}$ & $230 \mathrm{~m}$ & \\
\hline CLZ & GR & Clausthal-Zellerfeld & $51.8416^{\circ} \mathrm{N}$ & $10.3724^{\circ} \mathrm{E}$ & $680 \mathrm{~m}$ & \\
\hline FUR & GR & Fürstenfeldbruck & $48.1629^{\circ} \mathrm{N}$ & $11.2752^{\circ} \mathrm{E}$ & $565 \mathrm{~m}$ & \\
\hline GRFO & IU & Gräfenberg & $49.6909^{\circ} \mathrm{N}$ & $11.2203^{\circ} \mathrm{E}$ & $384 \mathrm{~m}$ & $116 \mathrm{~m}$ \\
\hline HLG & GE & Helgoland & $54.1847^{\circ} \mathrm{N}$ & $7.8839^{\circ} \mathrm{E}$ & $41 \mathrm{~m}$ & \\
\hline IBBN & GE & Ibbenbüren & $52.3072^{\circ} \mathrm{N}$ & $7.7566^{\circ} \mathrm{E}$ & $140 \mathrm{~m}$ & \\
\hline MOX & GR & Moxa & $50.6447^{\circ} \mathrm{N}$ & $11.6156^{\circ} \mathrm{E}$ & $455 \mathrm{~m}$ & $25 \mathrm{~m}$ \\
\hline RGN & GE & Rügen & $54.5477^{\circ} \mathrm{N}$ & $13.3214^{\circ} \mathrm{E}$ & $15 \mathrm{~m}$ & \\
\hline RUE & GE & Rüdersdorf & $52.4759^{\circ} \mathrm{N}$ & $13.7800^{\circ} \mathrm{E}$ & $0 \mathrm{~m}$ & \\
\hline STU & GE & Stuttgart & $48.7708^{\circ} \mathrm{N}$ & $9.1933^{\circ} \mathrm{E}$ & $360 \mathrm{~m}$ & $20 \mathrm{~m}$ \\
\hline TNS & GR & Kleiner Feldberg (Taunus) & $50.2225^{\circ} \mathrm{N}$ & $8.4473^{\circ} \mathrm{E}$ & $815 \mathrm{~m}$ & $5 \mathrm{~m}$ \\
\hline WET & GR & Wettzell & $49.1440^{\circ} \mathrm{N}$ & $12.8782^{\circ} \mathrm{E}$ & $613 \mathrm{~m}$ & \\
\hline
\end{tabular}

$s_{k 1}$ are determined to minimize the residual

$r_{k}(i)=a_{k}(i)-\sum_{l} s_{k l} B_{l}(i)$

in a least-squares sense

$\sum_{i}\left|r_{k}(i)\right|^{2} \stackrel{!}{=} \min$

Here, $k$ indicates one of the seismometer components $Z, N, E, U$, $V$ or $W$, where the latter three are the internal components of the STS-2. The magnetic field is given by its components $x, y$ and $z$, where $l$ indicates one of these. $a_{k}$ is the acceleration obtained from the seismic component $k$ and $B_{l}$ is the magnetic field obtained from the fluxgate component $l$. The sample index is given by $i$.

Fig. 9 illustrates the procedure while Fig. 10 gives an example of the fit achieved for sequential time windows during 2003 October 29 for the U-component of the STS-2 at BFO. After the SSC the variance of the residual (middle trace in each panel) is typically less than 3 per cent of that of the sensor's output signal. The coefficients $s_{k l}$ appear quite stable over different time windows (Fig. 11). The varying period content of the magnetic signal (Fig. 10) has no significant influence on the $s_{k l}$.

Since the ZNE-components provided by the STS-2 are mixed electronically from the internal UVW-components, acceleration signals for the latter are studied independently. The relation

$\vec{a}_{U V W}=\mathbf{T}^{-1} \vec{a}_{Z N E}$

is provided by Wielandt (2002b, eq. 4), where

$\mathbf{T}=\frac{1}{\sqrt{6}}\left(\begin{array}{ccc}-2 & 1 & 1 \\ 0 & \sqrt{3} & -\sqrt{3} \\ \sqrt{2} & \sqrt{2} & \sqrt{2}\end{array}\right)$

and $\mathbf{T}$ is orthonormal.

The same analysis is applied to other GRSN stations too (Fig. 12). The quality of the fit there depends on the level of background noise from other sources at each station which is typically larger on horizontal components. For stations at larger distance from BFO the meaning of the analysis becomes questionable since magnetic field recordings from $\mathrm{BFO}$ are used always. This is the case for stations HLG and RGN, in particular, because the anomaly in the vertical component of the magnetic field changes its polarity between WNG (Wingst, Fig. 3) and NGK (Niemegk) due to the North German conductivity anomaly (Losecke et al. 1979). The sensitivities given below are likely to overestimate the true effect since the magnetic intensity of the storm increases with latitude within Germany. Unfortunately, a regression analysis for the KS-36000 at the IRIS station GRFO is not possible because its sensitivity to the magnetic field is too weak. A stable regression for more than one time window cannot be achieved there. This and its apparent response to variations of the magnetic field of different period in different time windows (not shown here) may also indicate a transfer mechanism that is more complicated for the KS-36000 than for the STS-2 seismometers. A reliable analysis would require magnetic field records from the vicinity of a strongly responding KS-36000 seismometer.

Results are given in Table 4 for BFO instruments and in Table 5 for other GRSN stations. For BFO ZNE components the analysis is applied to 72 two-hour windows from 2003 October 29-31. For the UVW-components only the first 53 windows are used. Some had to be discarded for technical reasons. For the GRSN stations the analysis is applied to 24 two-hour windows on October 29, where the last two windows are discarded for the UVW-analysis. The number of windows used is given by $N_{\text {fit }}$ in the tables. $N_{\text {sel }}$ gives the number of windows in which the residual's variance is 9 per cent of the signal's variance or less. Mean values for the latter windows are given in Tables 4 and 5. However, the given coefficients most likely will loose their meaning after modifications in the set-up of the station. They should be understood as a description of the response for the whole installation (including locally produced heterogeneities of the magnetic field) on a large-scale rather homogeneous field outside the vault.

\subsection{Sensitivity}

The coefficients in Tables 4 and 5 are the sensitivities of each seismometer component to variations of the respective component of 


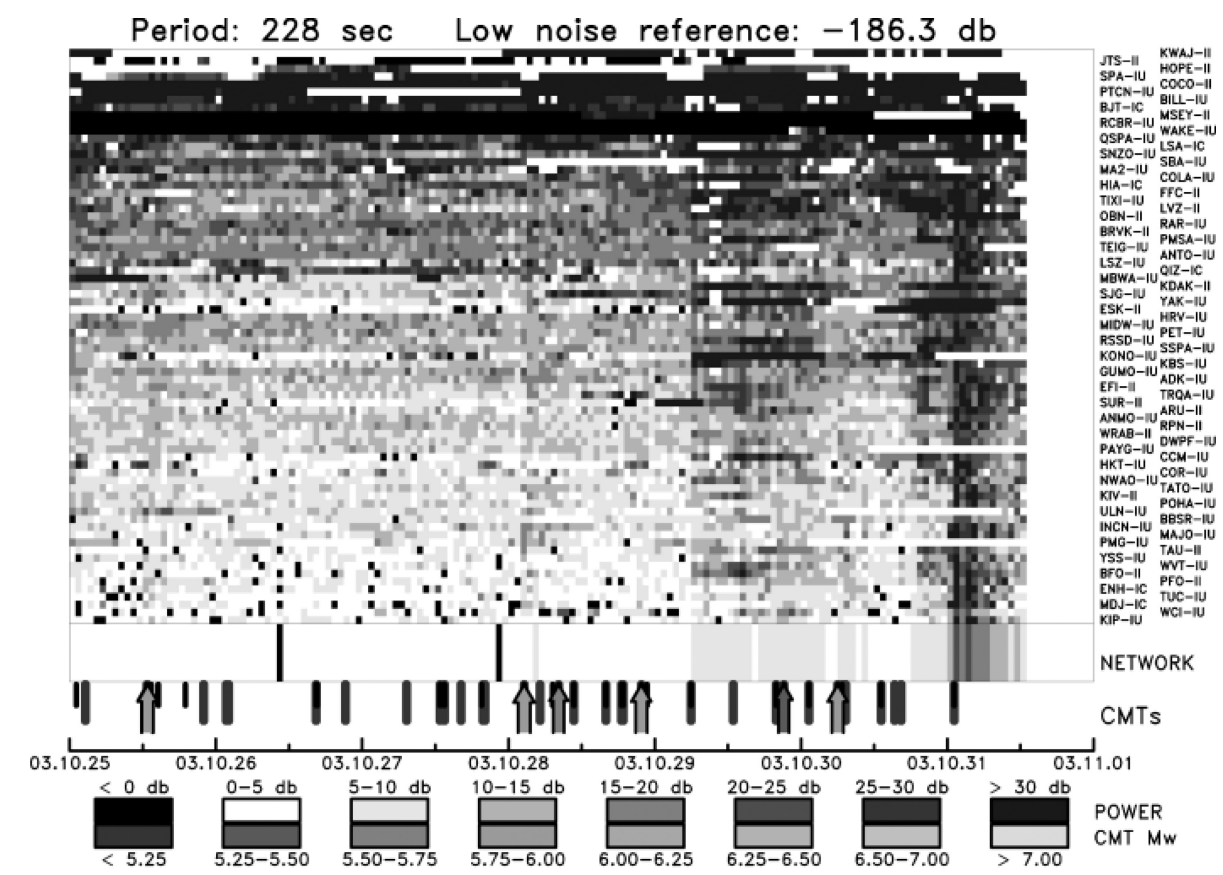

Magnetic storm recorded at BFO

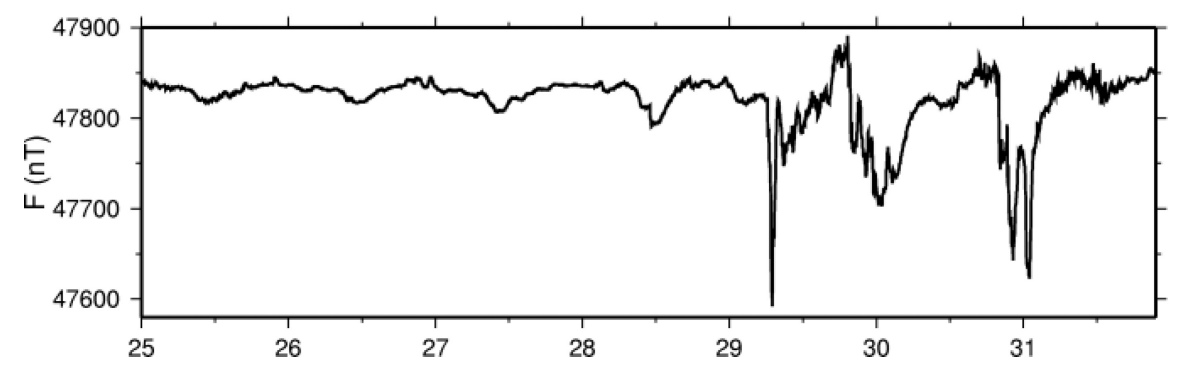

Figure 4. Noise induced by magnetic storms is a global phenomenon. Top: noise analysis for the quietest stations of the GSN (Global Seismic Network) from 2003 October 25 to 2003 November 1. The figure for the period band around $228 \mathrm{~s}$ was taken from http://www.seismology.harvard. edu/ ekstrom/Research/Noise/RADB_hourly_rms.html and modified to grey scale. Bottom: recording of the total magnetic intensity at BFO for the same time window. The noise level in the whole network (bottom trace) increases in immediate response to the sudden storm commencement (SSC) on 2003 October 29 06:11:10 UT. Dark grey values indicate larger amplitude. The majority of the stations that respond significantly to the SSC, are at latitudes higher than $50^{\circ}$ (Table 3). They comprise STS-1 and KS-54000 seismometers (Table 1). Stations with weak response to the SSC typically are at latitudes lower than $50^{\circ}$. (Courtesy of Göran Ekström and Rudolf Widmer-Schnidrig).

the magnetic field. The sensitivity is specified in terms of magnitude

$S_{k}=\sqrt{\sum_{l} s_{k l}^{2}}$

and direction

$\bar{s}_{k l}=s_{k l} / S_{k}$.

The vector

\section{$\mathbf{D} \hat{s}_{k}$}

in the ZNE-reference frame with

$\hat{s}_{k}=\left(\begin{array}{c}\bar{s}_{k x} \\ \bar{s}_{k y} \\ \bar{s}_{k z}\end{array}\right)$

specifies the component of the magnetic field that is sensed by the seismometer's component $k$. In general this appears to be perpendicular to the mechanical axis of the seismic sensor's pendulum which is horizontal for the UVW-components of the STS-2 and vertical component of the STS-1. Examples are given for the STS-2s at BFO (Fig. 11) and MOX (Fig. 13). While the sensitivity of the original UVW components is about $0.3 \mathrm{~m} \mathrm{~s}^{-2} \mathrm{~T}^{-1}$ for $\mathrm{BFO}$ and $0.4 \mathrm{~m} \mathrm{~s}^{-2} \mathrm{~T}^{-1}$ for MOX, the sensitivity of the vertical is small with $0.07 \mathrm{~m} \mathrm{~s}^{-2} \mathrm{~T}^{-1}$ for $\mathrm{BFO}$ and $0.1 \mathrm{~m} \mathrm{~s}^{-2} \mathrm{~T}^{-1}$ for MOX compared to the horizontal components with $0.4 \mathrm{~m} \mathrm{~s}^{-2} \mathrm{~T}^{-1}$ for $\mathrm{BFO}$ and $0.5 \mathrm{~m} \mathrm{~s}^{-2} \mathrm{~T}^{-1}$ for MOX. The vertical component of the sensitivities of UVW sensors scatters significantly in magnitude and sign. In the electronic superposition, which composes the vertical seismic component of the seismometer, these sensitivities cancel at least partly.

\subsection{Improving signal quality}

The Magnitude 7.0 Honshu-Earthquake on 2003 October 31 occurred during an ongoing magnetic storm. Variations of the magnetic field appeared mainly at periods longer than $200 \mathrm{~s}$. As a 
Table 3. Stations visually selected from Fig. 4. Top: stations responding strongly to the SSC. Bottom: stations responding weakly. All stations are listed in latitude order. Strongly responding stations are predominantly located at high latitudes in contrast to the weakly responding stations. Apparently KS-54000 and STS-1 seismometers (Table 1) are both sensitive to magnetic storms. N: network code (IU: IRIS/USGS, II: IRIS/IDA, IC: IRIS China Digital Seismic Network). Latitude: Positive to the North. Longitude: Positive to the East. E: elevation in metres. D: local depth in metres. All entries are obtained from IRIS dataless SEED volumes.

\begin{tabular}{|c|c|c|c|c|c|c|c|}
\hline Station & $\mathrm{N}$ & Station name & Latitude $\left(^{\circ}\right)$ & Longitude $\left({ }^{\circ}\right)$ & $\mathrm{E}(\mathrm{m})$ & $\mathrm{D}(\mathrm{m})$ & Sensor type \\
\hline \multicolumn{8}{|c|}{ Strongly responding stations: } \\
\hline KBS & IU & Ny-Alesund, Spitzbergen, Norway & 78.9256 & 11.9417 & 74.0 & 3.0 & STS-1 \\
\hline TIXI & IU & Tiksi, Russia & 71.6490 & 128.8665 & 50.0 & 0.0 & STS-1 \\
\hline LVZ & II & Lovozero, Russia & 67.8979 & 34.6514 & 630.0 & 200.0 & STS-1 \\
\hline COLA & IU & College Outpost, Alaska, USA & 64.8738 & -147.8511 & 74.0 & 120.0 & KS-54000 \\
\hline YAK & IU & Yakutsk, Russia & 62.0308 & 129.6812 & 91.0 & 14.0 & STS-1 \\
\hline KONO & IU & Kongsberg, Norway & 59.6491 & 9.5982 & 216.0 & 340.0 & STS-1 \\
\hline KDAK & II & Kodiak Island, Alaska, USA & 57.7828 & -152.5835 & 152.0 & 88.0 & KS-54000 \\
\hline ESK & II & Eskdalemuir, Scotland, UK & 55.3167 & -3.2050 & 242.0 & 0.0 & STS-1 \\
\hline OBN & II & Obninsk, Russia & 55.1138 & 36.5687 & 160.0 & 30.0 & STS-1 \\
\hline FFC & II & Flin Flon, Canada & 54.7250 & -101.9783 & 338.0 & 0.0 & STS-1 \\
\hline RSSD & IU & Black Hills, South Dakota, USA & 44.1204 & -104.0362 & 1991.7 & 68.3 & KS-54000 \\
\hline SNZO & IU & South Karori, New Zealand & -41.3103 & 174.7046 & -34.9 & 96.9 & KS-54000 \\
\hline PMSA & IU & Palmer Station, Antarctica & -64.7742 & -64.0490 & 10.0 & 0.0 & STS-1 \\
\hline \multicolumn{8}{|c|}{ Weakly responding stations: } \\
\hline ARU & II & Arti, Russia & 56.4302 & 58.5625 & 250.0 & 0.0 & STS-1 \\
\hline MDJ & IC & Mudanjiang, Heilongjiang Province, China & 44.6164 & 129.5919 & 200.0 & 50.0 & STS-1 \\
\hline $\mathrm{COR}$ & IU & Corvallis, Oregon, USA & 44.5857 & -123.3032 & 121.0 & 0.0 & STS-1 \\
\hline WCI & IU & Wyandotte Cave, Indiana, USA & 38.2290 & -86.2940 & 506.0 & 132.0 & STS-1 \\
\hline INCN & IU & Inchon, Republic of Korea & 37.4833 & 126.6333 & 419.0 & 1.0 & STS-1 \\
\hline ENH & IC & Enshi, Hubei Province, China & 30.2718 & 109.4868 & 487.0 & 0.0 & STS-1 \\
\hline TATO & IU & Taipei, Taiwan & 24.9735 & 121.4971 & 74.1 & 82.9 & KS-54000 \\
\hline KIP & IU & Kipapa, Hawaii, USA & 21.4233 & -158.0150 & 37.0 & 33.0 & STS-1 \\
\hline POHA & IU & Pohakuloa, Hawaii, USA & 19.7575 & -155.5325 & 1886.7 & 80.3 & KS-54000 \\
\hline PAYG & IU & Puerto Ayora, Galapagos Islands & -0.6741 & -90.2863 & 195.0 & 100.0 & KS-54000 \\
\hline RPN & II & Rapanui, Easter Island, Chile & -27.1267 & -109.3344 & 110.0 & 0.0 & STS-1 \\
\hline
\end{tabular}

consequence, the long period seismic recordings at BFO are visibly deteriorated by magnetic noise. Fig. 14 gives an example of how the signal quality of seismic recordings can be improved by removing the contribution predicted from magnetic field recordings using the coefficients from Table 4. Shown are recordings obtained from the STS-2 after application of a fourth-order Butterworth lowpass filter at $100 \mathrm{~s}$ period and a filter to simulate an instrument with 360 s eigenperiod. In each panel the uncorrected seismic trace (top) is shown together with the predicted noise signal (bottom) obtained from appropriately filtered magnetic field recordings and the residual of both (middle) which represents the seismic signal with improved quality. Average and trend were removed from all signals and the magnetic field signals were filtered effectively by a fourthorder Butterworth lowpass filter at $100 \mathrm{~s}$ period and a second-order Butterworth highpass at $360 \mathrm{~s}$ and were integrated once on order to match the simulated seismometer's response.

\section{TRANSFER MECHANISM}

The fact that the horizontal STS-1 seismometers show no sensitivity, while the vertical STS-1 does, gives reason to suspect the suspension spring as the source of the sensitivity to the magnetic field. This is well known and the manufacturer supplies the vertical instrument with a Permalloy ( $\mu$-metal) casing for magnetic shielding. Both instruments are built with comparable components apart from the suspension spring and the magnetic shielding. Thus a sensitivity to the magnetic field would be expected too for the horizontal seismometers if any other component, like the hinges or the feedback coil or the displacement transducer, would be the source.

\subsection{Suspension spring alloys}

Suspension springs must be made from material that has its thermal expansion coefficient and its thermal sensitivity in elastic properties both as small as possible. Material with the first property only is known as Invar (Guillaume 1967) or Vacodil (trademark of the Vacuumschmelze Hanau) and is used in the Invar-wire strainmeters for example. Invar is a nickel-iron alloy with typically about 36 per cent of nickel. Material with both properties is known as Elinvar (Guillaume 1967) or Thermelast (trademark of the Vacuumschmelze Hanau). Elinvar is a nickel-iron-chromium or nickeliron-molybdenum alloy with some minor constituents. The STS-2 uses a combination of an Elinvar and a non-Elinvar (and nonmagnetic) leaf-spring since the Elinvar is slightly overcompensated and since the seismometer must be compensated as a whole. All Invar and Elinvar alloys are ferromagnetic. In fact the Invar and Elinvar property appears to be closely related to the thermodynamic and magnetic behaviour of the material (van Schilfgaarde et al. 1999). A rather simplified explanation tells that the thermal expansion is compensated by magnetostriction due to thermal loss of spontaneous magnetization (Rau 1977). Hence sensors that make use of these materials must always be expected to be sensitive to magnetic fields. It is thus surprising that neither the Invar-wire strainmeters nor the ET-19 gravimeter at BFO visibly respond to the magnetic storms.

In seismometers that use an Elinvar suspension at least three different physical mechanisms may contribute to the sensitivity of the suspension to the magnetic field. (1) A remanently magnetized spring may experience a torque in a magnetic field like a compass-needle does. (2) A variation in magnetization may result in 


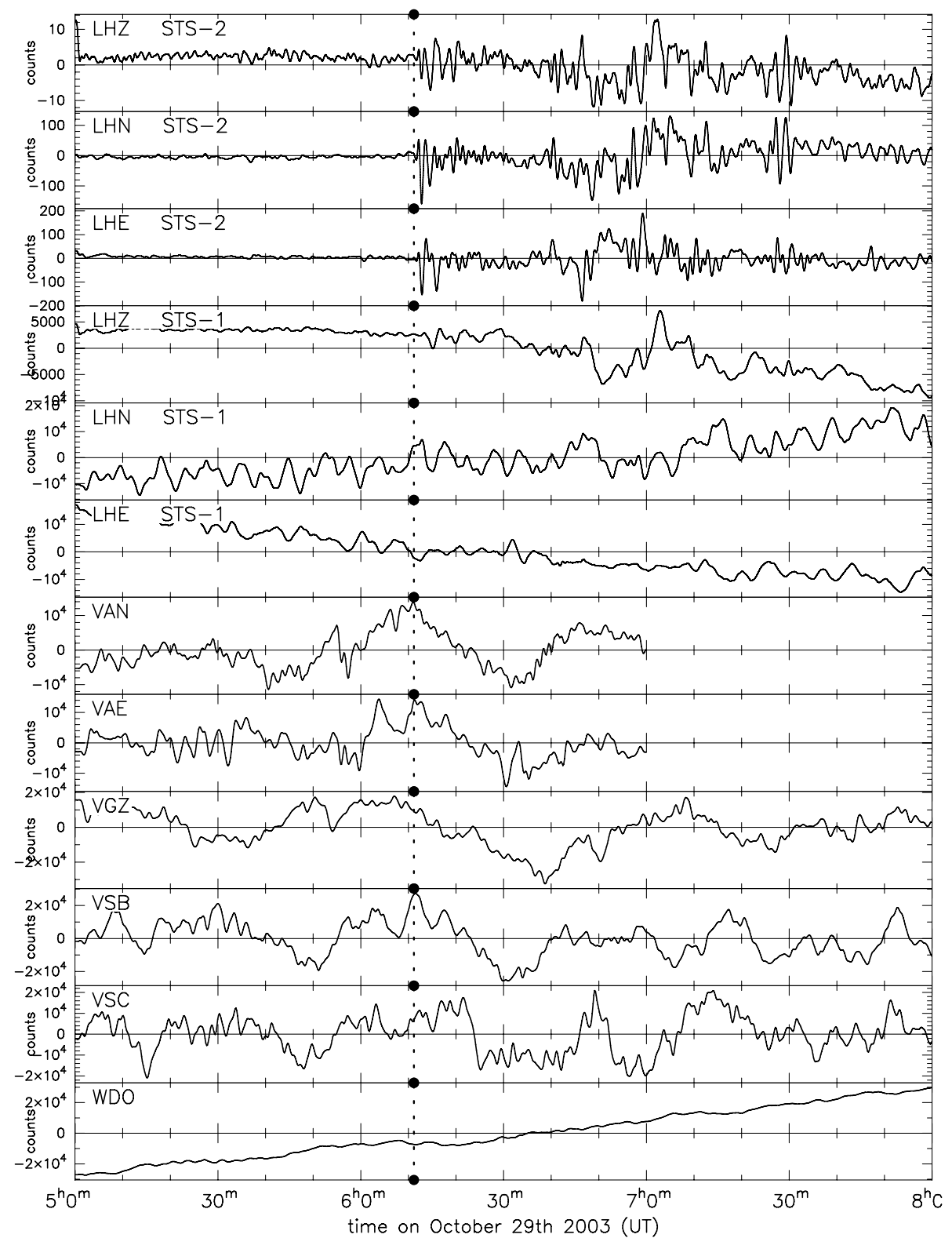

Figure 5. Response of instruments at BFO to the SSC (sudden storm commencement) on 2003 October 29 06:11:10 UT. All three components of the STS-2 (instruments are explained in Table 1) show an increased noise level due to the magnetic storm. However, only the vertical component of the STS-1 visibly responds to the storm. The Askania pendulum (VAE and VAN) does not respond. Both channels had problems after 7:00 and are cut to prevent the graph from going off-scale. The ET-19 (VGZ) contains an Elinvar suspension spring. Although gravimeters are for this reason known to be sensitive to the magnetic field, the ET-19 shows no visible response. The Invar wire strain metres (VSB and VSC) could also be expected to be sensitive to the magnetic field due to the properties of the Invar alloy. However, they show no response to the SSC either. Strainmeter VSA was not operating due to maintenance. Barometric pressure (WDO) is given to provide evidence that the increased noise level is not due to barometric pressure. The raw time-series are lowpass filtered with a $60 \mathrm{~s}$ Butterworth filter of fourth-order to remove microseisms.

magnetostriction thus changing the geometry of the spring and disturbing the balance of the seismometer's pendulum. (3) A variation in magnetization may result in a variation of the elastic modulus and thus change the suspension force applied to the seismometer's pendulum. For small signals all three effects are expected to produce an apparent acceleration of the seismic mass proportional to the magnetic field. Magnitude and sign of the sensitivity due to the compass-needle effect directly depend on the remanent magnetization of the spring. The latter two effects result from material properties that vary with the magnetization of the spring. Since the remanence and the Earth's permanent field add a bias to the overall magnetization, they may both control the sensitivity to variations of the external magnetic field of each individual sensor.

The magnitude of these effects can hardly be estimated without detailed information about the alloys in use and the geometry of the seismometer's pendulum. In particular, the effect of magnetostriction cannot be estimated since it strongly depends on the small-scale geometry of the suspension spring. For the two other effects I make an attempt to rule out one or both. The effect of the dependency of elastic modulus on magnetic field mainly is controlled by the properties of the alloy and not by pendulum geometry. For Thermelast $5409 \mathrm{I}$ obtain an upper limit of $\Delta a / B \approx 0.01 \mathrm{~m} \mathrm{~s}^{-2} \mathrm{~T}^{-1}$. The 

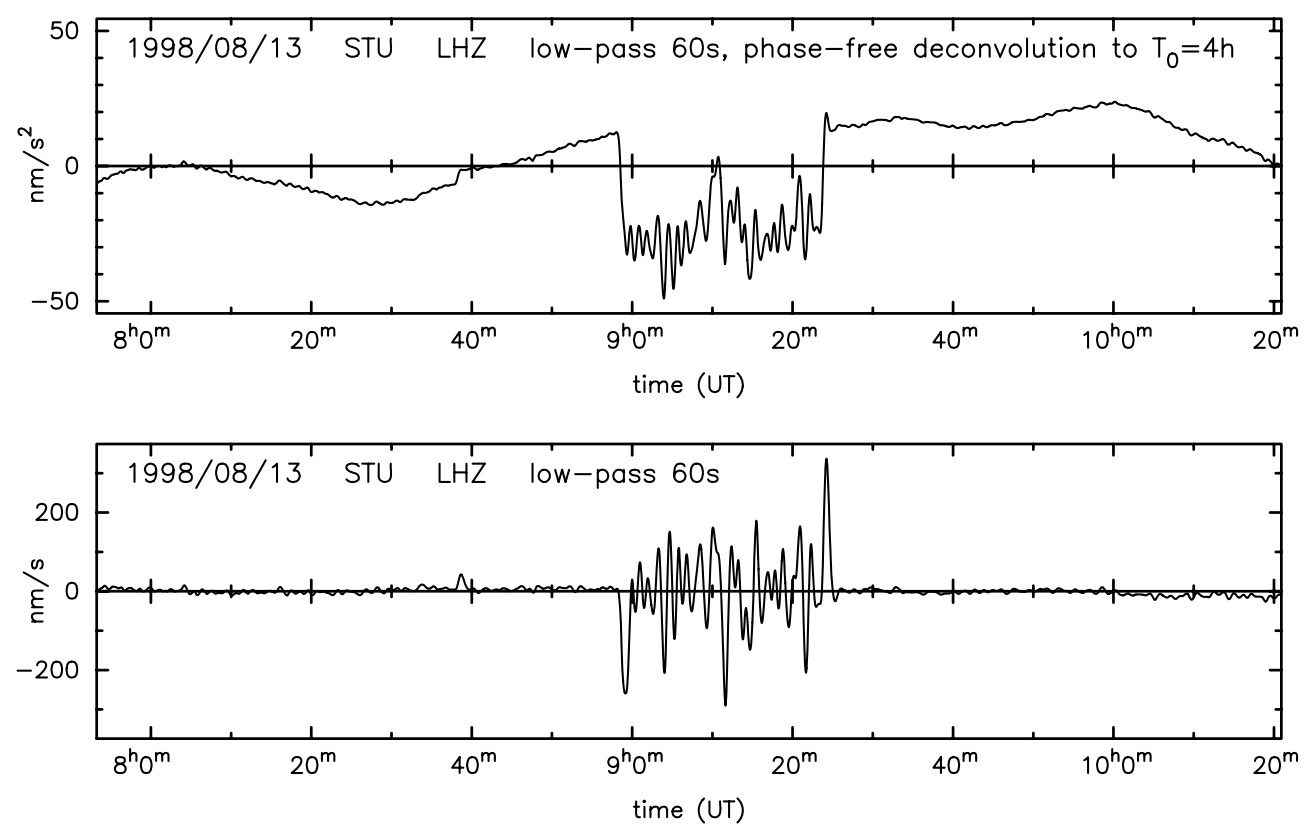

Figure 6. On 1998 August 13 a breakdown of the main electric power supply of station STU occurred. Since the recording system and the seismometer were buffered by a battery, data is available for this time. However, the active magnetic shield had no buffered power supply and was not operating between 08:58 UT and 09:25 UT. Top: vertical component deconvolved to acceleration and filtered with a phase-free highpass of fourth order, with $4 \mathrm{hr}$ period. Bottom: raw data. A fourth-order Butterworth lowpass of $60 \mathrm{~s}$ period was applied to both traces to remove microseisms. From the top trace it is obvious that the magnetic shield compensated also a small fraction of the static magnetic field. The rms noise level in the bottom trace is increased by a factor of 18 during the breakdown.

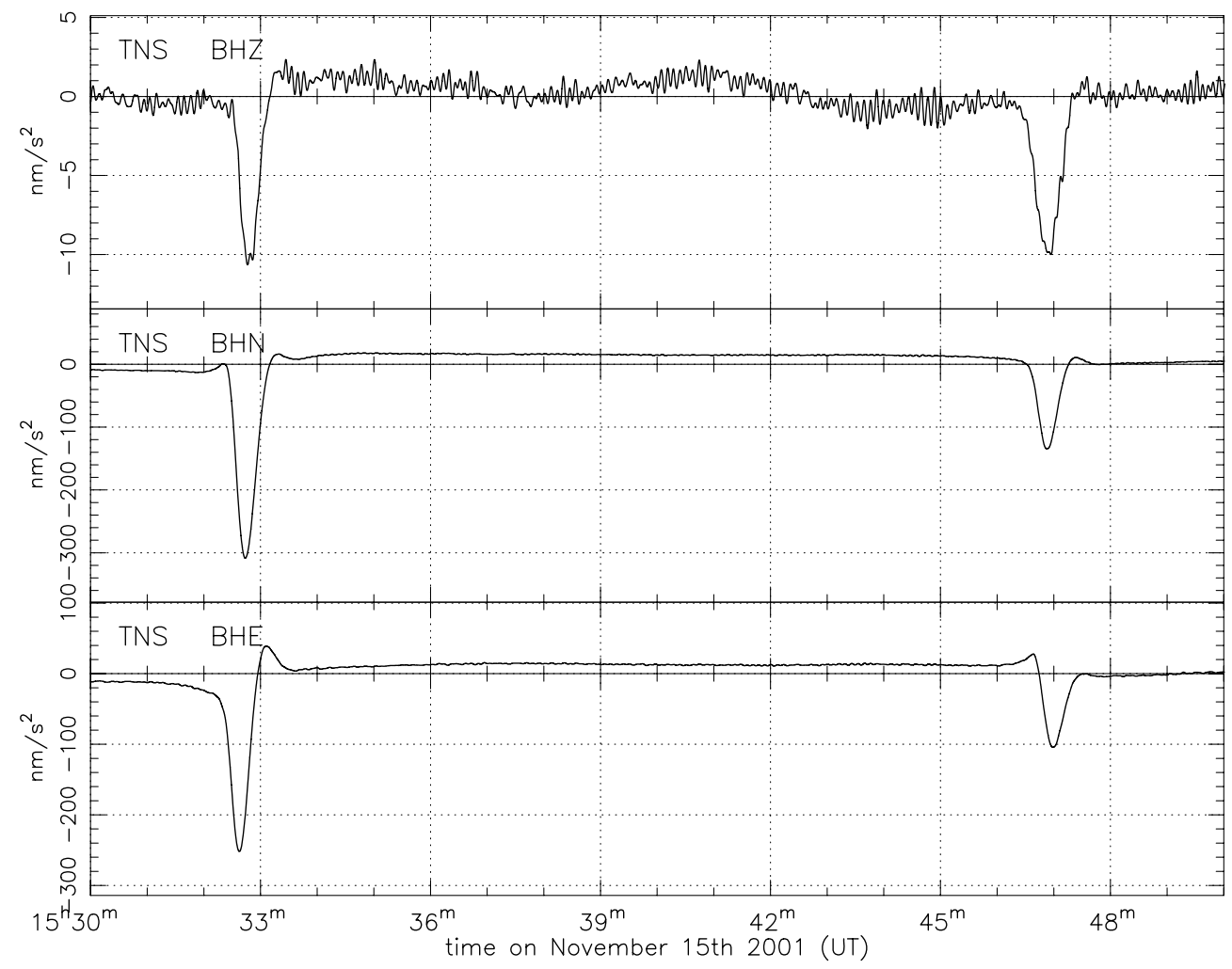

Figure 7. Acceleration signal of the three components of GRSN station TNS on 2001 November 15. Due to construction work at the summit of Kleiner Feldberg many lorries passed close to the seismic vault during that day. This is very unusual for station TNS and does not represent typical data quality. The two transients shown here are caused by a lorry (loaded) passing the station on its way to the summit at 15:32 UT and down again (unloaded) at 15:47 UT as was reconstructed from the total activity during the day. The horizontal component signals are identified as tilt induced by the surface load (Wielandt 2002; section 2.4), as is substantiated in Fig. 8. From several possible sources for the vertical component signal, all can by ruled out by physical reasons, except one which is a local distortion of the earths magnetic field due to the moving vehicle. Signals are filtered with a lowpass of fourth-order at $40 \mathrm{~s}$ period and deconvolved to acceleration. 
TNS 15/11/2001 15:30 UT

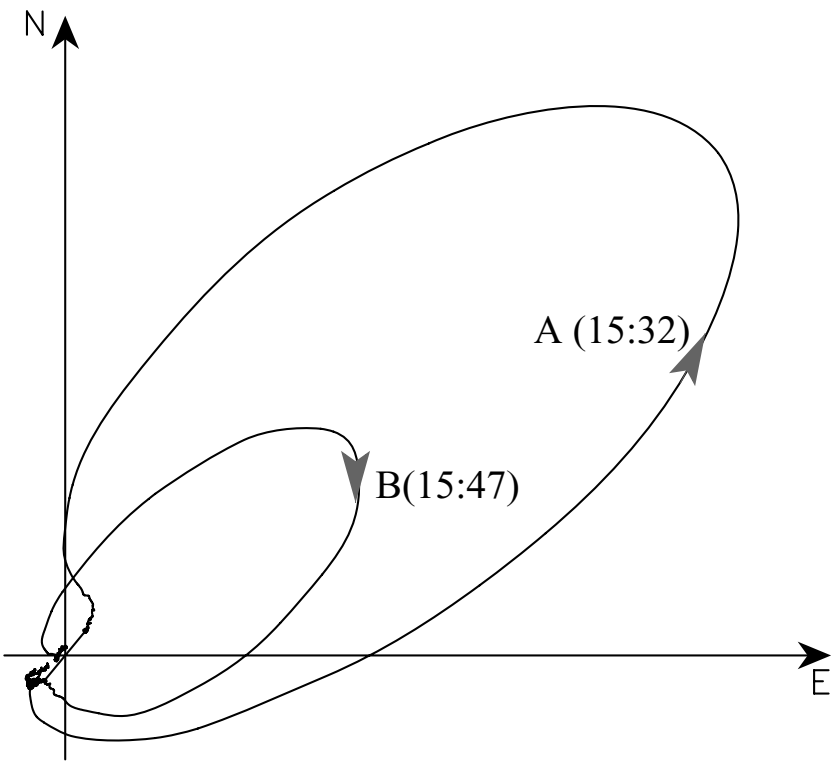

Figure 8. Direction and magnitude of the horizontal tilt that caused the transients shown in Fig. 7. The components of the trajectory are $-\partial u_{z}(t) / \partial x_{N}$ and $-\partial u_{z}(t) / \partial x_{E}$, where $u_{z}$ is the vertical displacement and $x_{N}$ and $x_{E}$ are the horizontal coordinates in north and east direction, respectively. The time $t$ is the parameter of the curve. When driving to the summit (passage A at 15:32 UT), the vehicles approach the seismic vault from southeast, come closest in the north-east and leave to the northwest. The way back from the summit is just the reverse (passage B at 15:47 UT). The tilt signal was derived from the horizontal component accelerations given in Fig. 7. Its amplitude scales with the surface load.

compass-needle effect strongly depends on the pendulum's geometry and the amount of remanent magnetization, in particular (which might be non-existent as well). As a worst case estimate I obtain $\Delta a / B \approx 20 \mathrm{~m} \mathrm{~s}^{-2} \mathrm{~T}^{-1}$ for the STS-1 and $\Delta a / B \approx 1 \mathrm{~m} \mathrm{~s}^{-2} \mathrm{~T}^{-1}$ for the STS-2 using the parameters of Thermelast 5409. None of these effects thus can be ruled out unfortunately. However, the compassneedle effect might be favoured for the more sensitive instruments.

\subsection{One suspect: the compass-needle effect}

The compass-needle effect may be additionally favoured because it predicts a sensitive direction perpendicular to the sensor's axis. In contrast, magnetostriction or variations in the elastic modulus might require a tensor to describe the relation between the vector of magnetic field and the resulting torque on the seismometer's pendulum with no preferred sensitive direction. Regarding the suspension spring as a compass-needle, its axis of rotation is the clamp that fixes the spring to the seismometer casing. It may turn around this axis which is parallel to the axis of the seismometer's pendulum for both the STS-2 and the STS-1 vertical component (Wielandt 2002b, Fig. 4). In this way the field exerts a force on the sensor's pendulum. The torque

$\vec{M}=\vec{m} \times \vec{B}$

acts on a magnetic dipole $\vec{m}$ (here the leaf-spring with remanent magnetization) due to the magnetic field $\vec{B}$. Only the component parallel to the axis $\hat{l}$ is not compensated by the clamp and the hinges and exerts the acceleration

$$
\begin{aligned}
a & =\lambda \hat{l} \cdot \vec{M}, \\
& =\lambda \hat{l} \cdot(\vec{m} \times \vec{B}), \text { and thus } \\
& =\lambda \vec{B} \cdot(\hat{l} \times \vec{m})
\end{aligned}
$$

on the seismic mass, where $\lambda$ is a factor depending on the geometry of the sensor's components and the seismic mass. A sensitivity $\vec{s}=$ $S \hat{s}$ in the sense of eqs (6)-(9) results in the acceleration

$a=\vec{s} \cdot \vec{B}$.

Comparing eqs (13) and (14) I find that the sensitivity

$\vec{s}=\lambda \hat{l} \times \vec{m}$

due to the compass-needle effect would be perpendicular to the axis $\hat{l}$ (like being observed) as well as to the dipole moment $\vec{m}$ of the spring.

\section{COUNTER-MEASURES}

\subsection{Demagnetization}

Seismometers should be made immune against variations of the magnetic field rather than correcting the data. Demagnetization of the suspension spring is currently under discussion to make the instruments themselves immune to the compass-needle effect and thus insensitive to variations of the magnetic field. While demagnetization is known to be essential in the construction of sensitive gravimeters, it is not routinely done for seismometers except for heating the spring to a level that exceeds the Curie temperature. This happens prior to assembling the instrument in order to adjust its elastic properties.

I tested the potential of a simple tape head demagnetizer (Bernstein type 2-305) to reduce the sensitivity of the STS-1V SN 1828 (Table 1). While this operation could be shown to be quite effective when applied to a spare leaf spring, I had no success with the mounted leaf spring fixed in the STS-1V. The sensitivity of the instrument was measured by applying artificial magnetic fields to the seismometer through Helmholtz coils while recording the magnetic field and the seismometer's response. A sweep signal with 35 cycles per decade and increasing period starting at $1.25 \mathrm{~s}$ was used. This extends the bandwidth of the investigations reported above.

Fig. 15 shows the sensitivity $\vec{s}$ (in $\mathrm{m} \mathrm{s}^{-2} \mathrm{~T}^{-1}$ ) for the instrument in five different conditions. The meaning of the arrows is comparable to Fig. 11. The instrument was relatively insensitive to magnetic fields in its original state (1: $S=0.15 \mathrm{~m} \mathrm{~s}^{-2} \mathrm{~T}^{-1}$ ). After attempts to demagnetize the leaf spring the sensitivity was considerably increased (2: $S=0.91 \mathrm{~m} \mathrm{~s}^{-2} \mathrm{~T}^{-1}, 4: S=0.47 \mathrm{~m} \mathrm{~s}^{-2} \mathrm{~T}^{-1}$, and 5: $S=$ $0.66 \mathrm{~m} \mathrm{~s}^{-2} \mathrm{~T}^{-1}$ ) and more closely aligned to the plane perpendicular to the pendulum axis. This orientation would be expected for the compass-needle effect. The seismometer appears to be magnetized remanently after application of the demagnetizer; although, great care was taken to decrease the magnitude of the demagnetizing alternating field to zero continuously. Unfortunately, I cannot exclude that the relatively strong magnetic field has caused a phase transition in the Elinvar alloy. Pálinkás et al. (2003; Figs 2 and 6) also show records that might indicate a remaining offset caused by the magnetic field applied during their experiment. I conclude that the simple tape head demagnetizer is not appropriate to demagnetize a mounted Elinvar leaf-spring inside a seismometer. 


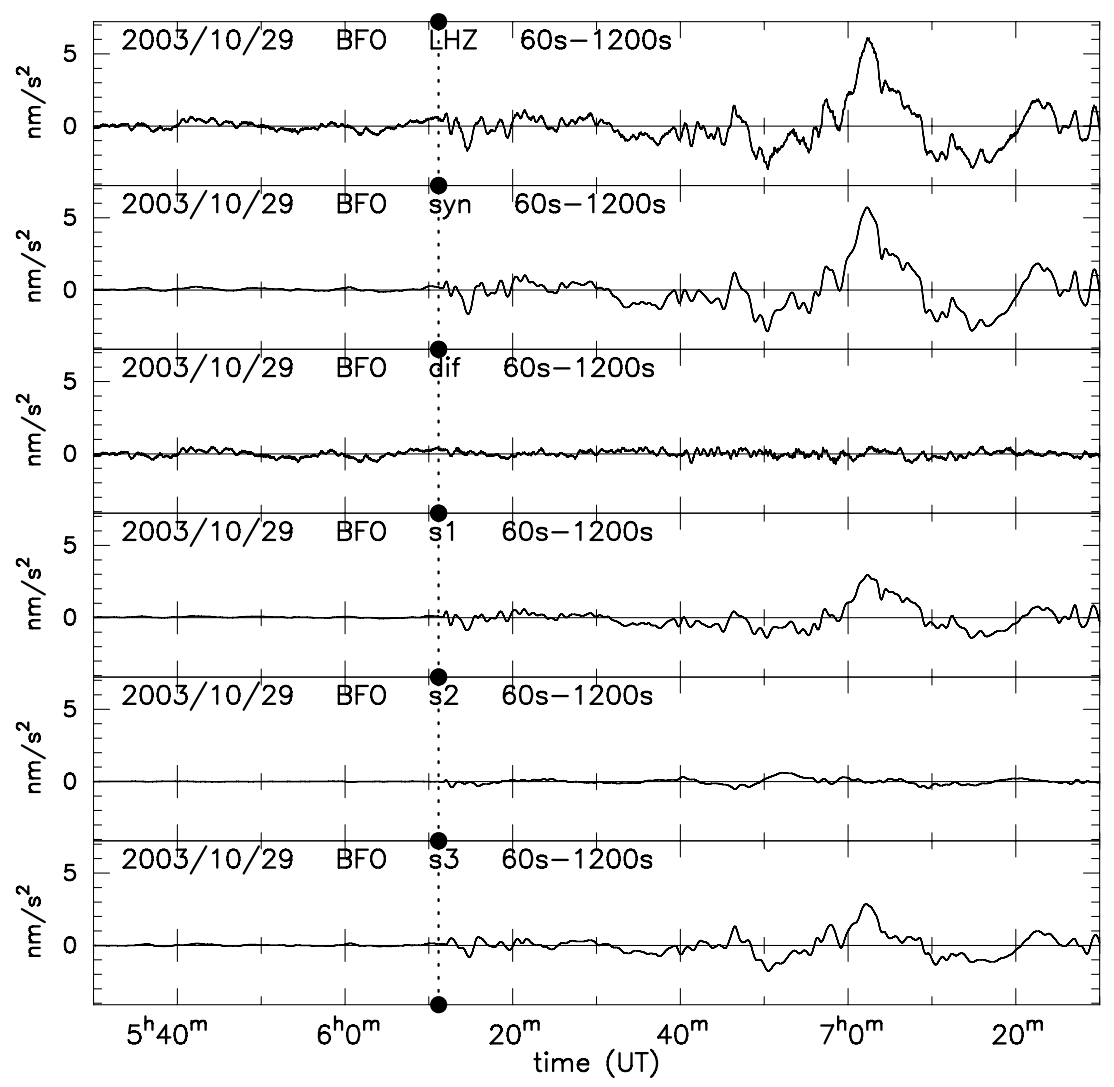

Figure 9. Removing noise induced by the magnetic field employing a linear regression. Panels from top to bottom show: LHZ: vertical acceleration obtained from the STS-2 at BFO. syn: acceleration acting on the seismometer's vertical component due to variations of the magnetic field, as predicted by the linear regression analysis. dif: residual signal that is not explained by the predicted acceleration. s1, s2 and s3: contributions of the magnetic fields $x$-, $y$ - and $z$-component to the syn-signal, respectively. All signals are band limited to a period range from 60 to $1200 \mathrm{~s}$ as specified in the text. The dashed line marks the SSC. The residual is the only signal that does not respond to the SSC.

\subsection{Magnetic shielding}

A passive shielding made from Permalloy ( $\mu$-metal) is generally used for STS-1 vertical components. Fig. 15 shows the difference between the sensitivity of the unshielded STS-1V SN 1828 (2: $S=0.91 \mathrm{~m} \mathrm{~s}^{-2} \mathrm{~T}^{-1}$ ) and that of the seismometer protected by the Permalloy casing ( $\left.3: S=0.05 \mathrm{~m} \mathrm{~s}^{-2} \mathrm{~T}^{-1}\right)$. The shield reduces the effective sensitivity by a factor of 18 . Pálinkás et al. (2003; Figs 6 and 7) report a decrease in sensitivity by a factor of 30 due to a PY 76 Permalloy shield (Permalloy with 76 per cent nickel). While the unprotected components of the STS-2 (SN 19123, Table 1) sensors at BFO show sensitivities of about $0.3 \mathrm{~m} \mathrm{~s}^{-2} \mathrm{~T}^{-1}$, the shielded STS-1V (SN 28740) has a sensitivity of $0.07 \mathrm{~m} \mathrm{~s}^{-2} \mathrm{~T}^{-1}$. Taking into account that we expect a larger compass-needle effect for the unprotected STS-1 compared to the STS-2, there appears to exist a clear effect of the shielding for the STS-1V SN 28740 too. However, the properties of $\mu$-metal may deteriorate under improper and rough handling.

Active shielding with the seismometer sitting in a cube of three Helmholtz coils is very effective at station STU. Fig. 6 clearly shows an improvement of the signal-to-noise ratio of about a factor of 18 and the station does not respond to magnetic storms visibly. Compared to passive shielding, active devices may add extra noise in case of malfunction while passive devices can only loose their effectiveness.

\section{CONCLUSIONS}

Long period seismic sensors are well known to be sensitive to variations of the magnetic field. Apart from magnetic storms, which are the major natural source, two man-made sources of significant magnetic field noise are demonstrated. One are strong electric currents of alternating magnitude in the subsurface at station STU. The other are distortions of the Earth's magnetic field by moving magnetic objects like lorries at station TNS. Thus in seismometer installations care has to be taken not to pick-up magnetic fields of varying magnitude from sources like DC power lines or steel-doors in the vicinity of the sensor.

I have shown that the variations in the magnetic field translate directly into apparent acceleration of the seismic sensor within the period band at least from 1 to $1200 \mathrm{~s}$. The sensitivity, as expressed in magnitude and direction, is quite stable for all sensors under investigation over many time windows and the investigated bandwidth. Its magnitude varies from sensor to sensor but in all cases is in the range from 0.05 to $1.2 \mathrm{~m} \mathrm{~s}^{-2} \mathrm{~T}^{-1}$. The sensitive directions for most leaf-spring seismometers under investigation are perpendicular to the sensors' axis. Three possible transfer mechanisms are under discussion, but no single one could be made responsible. Attempts to make an STS-1V insensitive by demagnetizing the suspension spring with an alternating field tape head demagnetizer turned out to be not effective. Active and passive (Permalloy) shields as well 


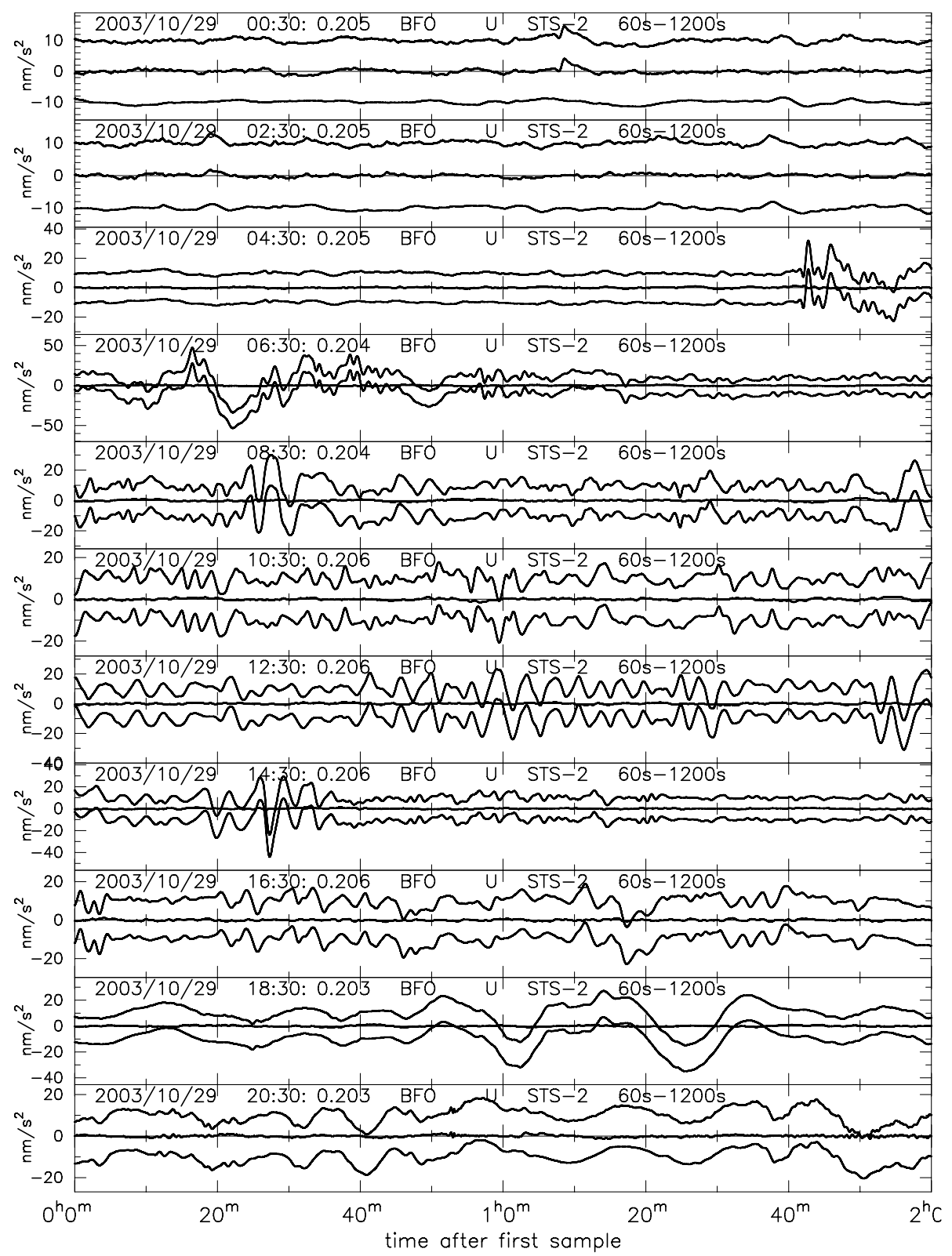

Figure 10. Results of linear regression analysis for the U-component of the STS-2 at BFO. Each of the 11 panels shows the results for a two-hour window. The first begins at 0:30 UT and the last ends at 22:30 UT on 2003 October 29. The sudden storm commencement appears at 06:11:10 UT and is visible in the third panel from the top, $1 \mathrm{hr}$ and $41 \mathrm{~min}$ after the first sample. Each panel shows three traces, which are vertically shifted by $10 \mathrm{~nm} \mathrm{~s}^{-2}$ each for better visibility. Top trace: acceleration signal in the period range from 60 to $1200 \mathrm{~s}$ as obtained from the seismometer output. Middle trace: residual after removing the contribution due to the magnetic field. Bottom trace: acceleration acting on the seismometer component as predicted from the magnetic field recordings. The panels have different vertical scales.

are capable to reduce the noise by a factor of almost 20 . The sensitivities obtained by a linear regression during a magnetic storm can effectively be applied to reduce noise in seismic signals. In the case of magnetic storms this may work also with the magnetic field recorded at a large distance (a few hundred kilometres) from the seismic sensor.

\section{A C K N OW LEDGMENTS}

For numerous discussions I am grateful to Walter Zürn who put me on the right track when investigating TNS noise. Erhard Wielandt is gratefully acknowledged for many discussions and for most I have learned about broad-band sensors. Thanks to Ruedi WidmerSchnidrig who takes care of the magnetometers at BFO and provided the fluxgate data. All of them contributed valuable comments on the manuscript. Heinz Otto, Andreas Hippel, Nicolas Hummel and Peter Duffner contributed to the experiments with the STS-1V. D. and G. Streckeisen kindly provided a replacement coil to set the formerly defective STS-1V SN 1828 up for the experiment. Gabi Laske, Luis Rivera and two anonymous reviewers contributed comments that helped to improve the manuscript. GRSN data (including GRFO) was provided by the Seismological Central Observatory (SZGRF) at Erlangen, Germany. Magnetic field data for station FUR was obtained from Intermagnet. 

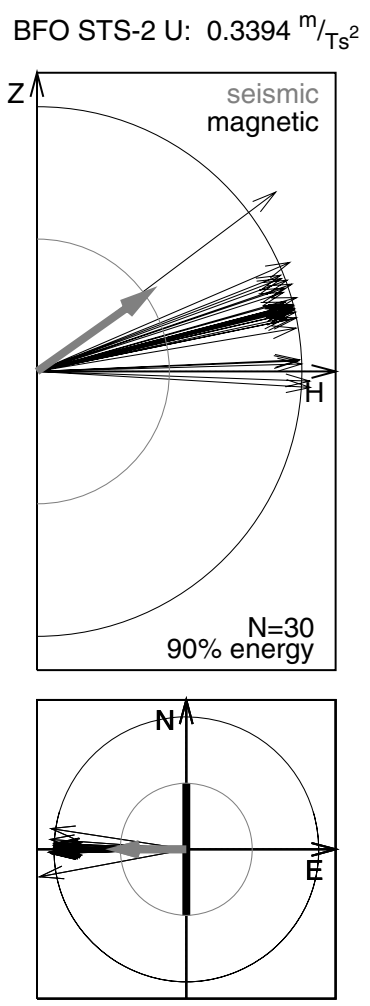

BFO STS-2 V: $0.3605 \mathrm{~m} / \mathrm{Ts}^{2}$
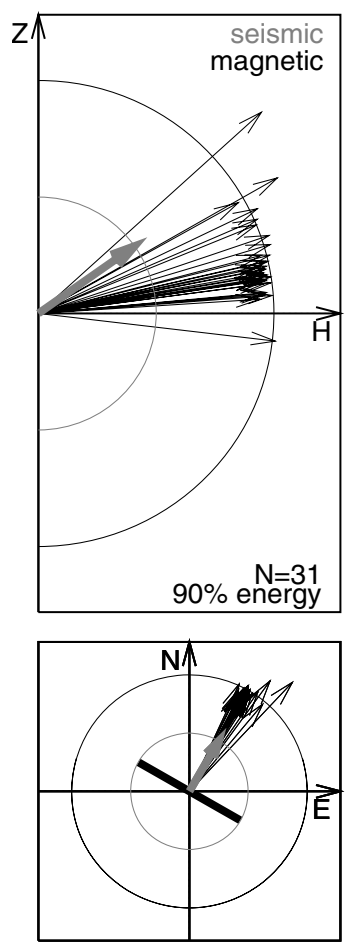

BFO STS-2 W: $0.3067 \mathrm{~m} / \mathrm{Ts}^{2}$
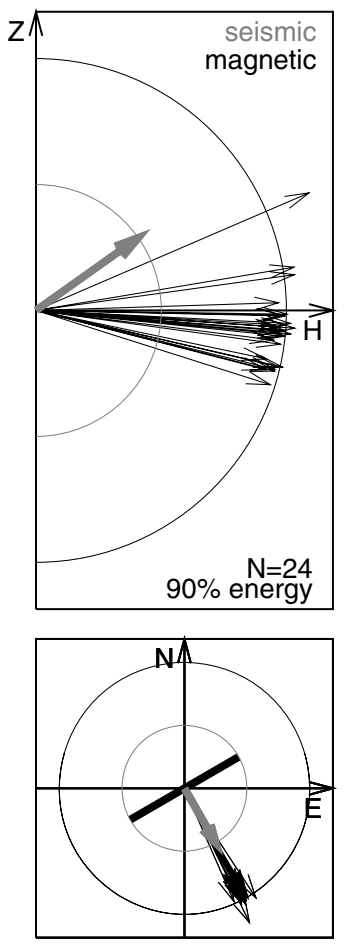

Figure 11. Sensitivities to the magnetic field vector for UVW-sensors of the STS-2 at BFO. Magnitude $S_{k}$ and direction $\mathbf{D} \hat{s}_{k}$ as defined in eqs (6) to (9) are displayed as vectors. The top panels show the vertical and horizontal $\left(\sqrt{s_{k x}^{2}+s_{k y}^{2}}\right)$ component, while the bottom panels provide a projection on the horizontal plane. Each vector specifies the sensitivity of one of the 2-hr data windows under investigation. Results for windows with the residual's variance being below 10 per cent of that of the signal are displayed only. $N$ : number of displayed vectors. The length of each vector specifies the magnitude of the sensitivity relative to the mean value given in the title. The corresponding radius for the mean value is given by the large black circle or semi-circle, respectively. The mean direction is displayed by a thin grey arrows in each panel. The thick grey arrows define the direction of sensitivity to ground acceleration for each component. While the vertical component reveals a significant scatter, the horizontal components are aligned to the sensitive direction of the mechanical sensor (compare Fig. 13 for station MOX). The sensitive directions thus are predominantly located in a plane perpendicular to the axis of the mechanical sensor. The axis of each of the three sensors is horizontal. Its orientation is marked by the bar in the inner circle of the lower panels.

\section{REFERENCES}

Agnew, D.C., 1986. Strainmeters and tiltmeters, Rev. Geophys., 24(3), 579624.

Aki, K. \& Richards, P.G., 2002. Quantitative Seismology, 2nd edn., University Science Books, Sausalito.

Guillaume, C.-É., 1967. Invar and Elinvar, in Nobel Lectures, Physics 19011921, Vol. 3, pp. 444-473. Elsevier, Amsterdam

Klinge, K., Kroner, C. \& Zürn, W., 2002. Broadband seismic noise at stations of the GRSN. In (Korn 2002), pp. 83-101.

Korn, M., ed., 2002. Ten Years of German Regional Seismic Network (GRSN), Deutsche Forschungsgemeinschaft, Wiley-VCH, Weinheim, Germany.

Losecke, W., Knödel, K. \& Müller, W., 1979. The conductivity distribution in the North German sedimentary basin derived from widely spaced areal magnetotelluric measurements, Geophys. J. R. astr. Soc., 58, 169-179.

Mälzer, H., Kiesel, H., Zürn, W., Emter, D., Schlemmer, H. \& Otto, H., 1979. Gezeitenmessungen im Geowissenschaftlichen Gemeinschaftsobservatorium Schiltach, Deutsche Geodätische Kommission, Reihe B, 245, 41.

Pálinkás, V., Kaspar, P. \& Lederer, M., 2003. Effect of the magnetic field on LCR gravimeters. In Proceedings of the Workshop: IMG-2002 Instrumentation and Metrology in Gravimetry, pp. 89-93. eds Francis, O. \& van Dam, T., ECGS and BIPM, Münsbach, Grand-Duchy of Luxembourg.

Rasmussen, O., 1997. Fluxgate magnetometer model FGE version G. Tech. Rep. 96-4, Danish Meteorological Institute, Copenhagen, Denmark.
Rau, G., ed., 1977. Metallische Verbundwerkstoffe, Werkstofftechnische Verlagsgesellschaft m.b.H., Karlsruhe, Germany.

Richter, B., Wenzel, H.-G., Zürn, W. \& Klopping, F., 1995. From Chandler wobble to free oscillations: comparison of cryogenic gravimeters and other instruments in a wide period range, Phys. Earth planet. Inter., 91, 131148.

Torge, W., 1989. Gravimetry, de Gruyter, New York.

van Schilfgaarde, M., Abrikosov, I.A. \& Johansson, B., 1999. Origin of the Invar effect in iron-nickel alloys, Nature, 400, 46-49.

Wessel, P. \& Smith, W.H.F., 1995. New version of the Generic Mapping Tools released, EOS, Trans. Am. geophys. Un., 76(33), 329.

Widmer, R., Zürn, W. \& Masters, G., 1992. Observation of low-order toroidal modes from the 1989 Macquerie Rise event, Geophys. J. Int., 111, 226236.

Wielandt, E., 1975. Ein astasiertes Vertikalpendel mit tragender Blattfeder, J. Geophys., 41, 545-547.

Wielandt, E., 2002a. Seismic sensors and their calibration. in New Manual of Seismological Observatory Practice, eds Bormann, P. \& Bergmann, E., GeoForschungsZentrum, Potsdam, Germany. 〈http://www.geophys.unistuttgart.de/lehre/skripte/old_skripte/seismometry/man_html/index.html $\rangle$, 〈http://www.geophys.uni-stuttgart.de/downloads/Postscript-files〉.

Wielandt, E., 2002b. Seismometry, in International Handbook of Earthquake and Engineering Seismology, Vol. A, pp. 283-304. eds Lee, W.H.K., Kanamori, H., Jennings, P.C. \& Kisslinger, C., Academic Press, Amsterdam. 


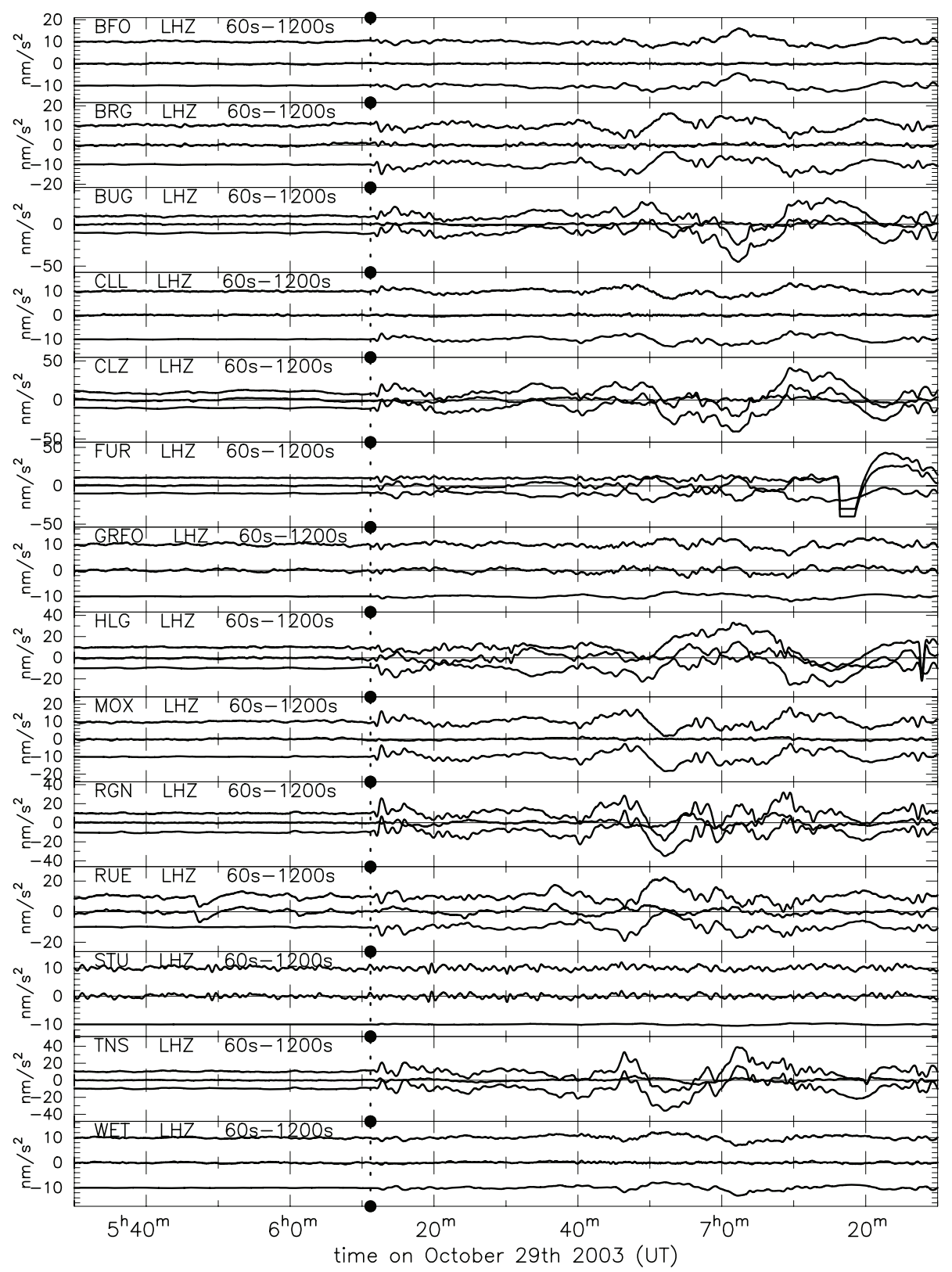

Figure 12. Results of linear regression analysis for the vertical component of GRSN stations (Fig. 3 and Table 2) for two hours after 5:30 UT on 2003 October 29. The SSC (sudden storm commencement) at 06:11:10 UT is marked. Each panel shows three traces, which are vertically shifted by $10 \mathrm{~nm} \mathrm{~s}{ }^{-2}$ each for better visibility. Top trace: acceleration signal in the period range from 60 to $1200 \mathrm{~s}$ as obtained from the seismometer output. Middle trace: residual after removing the contribution due to the magnetic field. Bottom trace: acceleration acting on the seismometer component as predicted from the magnetic field recordings. The panels have different vertical scales. A spike in the FUR record was clipped intentionally before plotting. This spike in the seismic recording, which is not present in the magnetic field, prevents the success of the regression in this case. For stations HLG, RGN and RUE at larger distance from BFO, the magnetic field recorded at BFO is only partly usable for a regression. There is no effect of the regression for station STU, since the seismometer is shielded against the magnetic field. For all other stations (except GPFO) I observe a remarkable similarity of the acceleration signal (top trace) and the magnetic field (bottom trace) while the residual remains small after the SSC. STS-2 seismometers are installed at all stations except GRFO where a KS-36000 is deployed (Table 1).

Wielandt, E. \& Steim, J.M., 1986. A digital very-broad-band seismograph, Ann. Geophys., 4(B3), 227-232.

Wielandt, E. \& Streckeisen, G., 1982. The leaf-spring seismometer: Design and performance, Bull. seism. Soc. Am., 72(6), 23492367.
Wielandt, E. \& Widmer-Schnidrig, R., 2002. Seismic sensing and data acquisition in the GRSN. In (Korn 2002), pp. 73-83.

Zürn, W. \& Wielandt, E., 2006. On the minimum of vertical seismic noise near $3 \mathrm{mHz}$, Geophys. J. Int., 168, 647-658, doi: 10.1111/j.1365246X.2006.03189.x 
Table 4. Results of linear regression for BFO sensors. $N_{\text {fit }}$ : number of time windows analysed. $N_{\text {sel }}$ : number of time windows for which the residual's variance is less than 9 per cent. Mean values for the coefficients are calculated for the latter and are provided in the other columns. The components are given with a fixed number of digits, but their significance may not be better than 5 per cent. See Figs 11 and 13 for the variance in the coefficients.

\begin{tabular}{|c|c|c|c|c|c|c|c|c|c|c|}
\hline Instrument & $k$ & $N_{\text {fit }}$ & $N_{\text {sel }}$ & $s_{k x}\left(\frac{\mathrm{m}}{\mathrm{Ts}^{2}}\right)$ & $s_{k y}\left(\frac{\mathrm{m}}{\mathrm{Ts}^{2}}\right)$ & $s_{k z}\left(\frac{\mathrm{m}}{\mathrm{Ts}^{2}}\right)$ & $\bar{s}_{k x}$ & $\bar{s}_{k y}$ & $\bar{s}_{k z}$ & $S_{k}\left(\frac{\mathrm{m}}{\mathrm{Ts}^{2}}\right)$ \\
\hline STS-1 & $\mathrm{Z}$ & 72 & 8 & 0.0035 & 0.0008 & -0.0693 & 0.0503 & 0.0112 & -0.9984 & 0.069 \\
\hline STS-2 & $\mathrm{Z}$ & 72 & 15 & 0.0246 & 0.0022 & -0.0693 & 0.3442 & 0.0272 & -0.9309 & 0.074 \\
\hline STS-2 & $\mathrm{N}$ & 72 & 29 & 0.3516 & 0.1949 & -0.0790 & 0.8450 & 0.4680 & -0.1876 & 0.42 \\
\hline STS-2 & $\mathrm{E}$ & 72 & 34 & -0.1603 & 0.3581 & 0.0551 & -0.4001 & 0.8930 & 0.1367 & 0.40 \\
\hline STS-2 & $\mathrm{U}$ & 53 & 30 & 0.1463 & -0.2915 & -0.0797 & 0.4318 & -0.8593 & -0.2336 & 0.34 \\
\hline STS-2 & V & 53 & 31 & 0.1916 & 0.2867 & -0.0821 & 0.5353 & 0.7966 & -0.2206 & 0.36 \\
\hline STS-2 & W & 53 & 24 & -0.3016 & 0.0106 & 0.0225 & -0.9841 & 0.0348 & 0.0790 & 0.31 \\
\hline
\end{tabular}

Table 5. Results of linear regression for GRSN stations. $N_{\text {fit }}$ : number of time windows analysed. $N_{\text {sel }}$ : number of time windows for which the residual's variance is less than 9 per cent. Mean values for the coefficients are given only for the latter. At most stations $N_{\text {sel }}$ increases significantly if the variance threshold is increased. However, not for all components a residual's variance of less than 9 per cent could be obtained. This is due to other noise sources at the individual stations and due to the application of magnetic field recordings obtained at BFO and not close to the station. All stations are equipped with STS-2 three-component sensors. The components are given with a fixed number of digits, but their significance may not be better than 5 per cent.

\begin{tabular}{|c|c|c|c|c|c|c|c|c|c|c|}
\hline Station & $k$ & $N_{\text {fit }}$ & $N_{\text {sel }}$ & $s_{k x}\left(\frac{\mathrm{m}}{\mathrm{Ts}^{2}}\right)$ & $s_{k y}\left(\frac{\mathrm{m}}{\mathrm{Ts}^{2}}\right)$ & $s_{k z}\left(\frac{\mathrm{m}}{\mathrm{Ts}^{2}}\right)$ & $\bar{s}_{k x}$ & $\bar{s}_{k y}$ & $\bar{s}_{k z}$ & $S_{k}\left(\frac{\mathrm{m}}{\mathrm{Ts}^{2}}\right)$ \\
\hline BFO & Z & 24 & 12 & 0.0242 & 0.0020 & -0.0697 & 0.3386 & 0.0237 & -0.9318 & 0.074 \\
\hline $\mathrm{BFO}$ & $\mathrm{N}$ & 24 & 19 & 0.3517 & 0.1924 & -0.0766 & 0.8568 & 0.4686 & -0.1855 & 0.41 \\
\hline $\mathrm{BFO}$ & $\mathrm{E}$ & 24 & 19 & -0.1576 & 0.3569 & 0.0620 & -0.3979 & 0.9012 & 0.1566 & 0.40 \\
\hline $\mathrm{BFO}$ & $\mathrm{U}$ & 22 & 18 & 0.1431 & -0.2895 & -0.0897 & 0.4263 & -0.8626 & -0.2671 & 0.34 \\
\hline $\mathrm{BFO}$ & $\mathrm{V}$ & 22 & 18 & 0.1983 & 0.2835 & -0.0717 & 0.5588 & 0.7981 & -0.1997 & 0.36 \\
\hline $\mathrm{BFO}$ & W & 22 & 17 & -0.3003 & 0.0121 & 0.0341 & -0.9865 & 0.0393 & 0.1134 & 0.30 \\
\hline BRG & $\mathrm{Z}$ & 24 & 2 & 0.0155 & 0.0563 & -0.0334 & 0.2310 & 0.8364 & -0.4960 & 0.067 \\
\hline BUG & Z & 24 & 13 & -0.1036 & -0.0771 & 0.4533 & -0.3026 & -0.1938 & 0.8983 & 0.49 \\
\hline BUG & $\mathrm{N}$ & 24 & 2 & -0.0488 & -0.1905 & 0.4774 & -0.0945 & -0.3689 & 0.9247 & 0.52 \\
\hline BUG & $\mathrm{E}$ & 24 & 2 & -0.0181 & -0.2151 & 0.1726 & -0.0657 & -0.7782 & 0.6244 & 0.28 \\
\hline BUG & $\mathrm{U}$ & 22 & 2 & -0.0475 & 0.1260 & 0.1732 & -0.2164 & 0.5745 & 0.7893 & 0.22 \\
\hline BUG & $\mathrm{V}$ & 22 & 8 & -0.1372 & -0.2677 & 0.4978 & -0.2911 & -0.4926 & 0.7676 & 0.61 \\
\hline CLL & Z & 24 & 2 & -0.0072 & -0.0283 & 0.0414 & -0.1414 & -0.5585 & 0.8174 & 0.051 \\
\hline CLZ & Z & 24 & 3 & 0.0981 & -0.2172 & 1.2001 & 0.0744 & -0.1825 & 0.9794 & 1.2 \\
\hline FUR & Z & 24 & 2 & 0.1652 & -0.0003 & 0.3676 & 0.4097 & -0.0001 & 0.9116 & 0.40 \\
\hline MOX & Z & 24 & 4 & -0.0418 & -0.0695 & -0.0598 & -0.3775 & -0.7303 & -0.4241 & 0.11 \\
\hline MOX & $\mathrm{N}$ & 24 & 17 & 0.3669 & 0.2620 & -0.1466 & 0.6900 & 0.4829 & -0.2552 & 0.54 \\
\hline MOX & $\mathrm{E}$ & 24 & 11 & -0.2471 & 0.2972 & 0.1030 & -0.5086 & 0.6191 & 0.2400 & 0.49 \\
\hline MOX & $\mathrm{U}$ & 22 & 10 & 0.1802 & -0.2848 & -0.1107 & 0.4197 & -0.6701 & -0.2467 & 0.44 \\
\hline MOX & V & 22 & 12 & 0.1295 & 0.2758 & -0.1734 & 0.3164 & 0.6677 & -0.4086 & 0.42 \\
\hline MOX & W & 22 & 14 & -0.3838 & -0.1055 & 0.1121 & -0.8351 & -0.2247 & 0.2374 & 0.46 \\
\hline TNS & $\mathrm{Z}$ & 24 & 19 & 0.1712 & -0.1220 & -0.1083 & 0.5885 & -0.4219 & -0.2724 & 0.31 \\
\hline TNS & $\mathrm{E}$ & 24 & 3 & 0.0363 & 0.2314 & 0.3142 & 0.0922 & 0.5879 & 0.8002 & 0.39 \\
\hline TNS & $\mathrm{U}$ & 22 & 10 & 0.1081 & -0.2394 & -0.1870 & 0.3348 & -0.7365 & -0.5667 & 0.32 \\
\hline TNS & W & 22 & 2 & 0.0718 & 0.0773 & -0.3542 & 0.1980 & 0.2090 & -0.9569 & 0.37 \\
\hline WET & $\mathrm{N}$ & 24 & 1 & 0.3305 & 0.1773 & 0.1804 & 0.7941 & 0.4260 & 0.4334 & 0.42 \\
\hline WET & $\mathrm{E}$ & 24 & 1 & -0.0936 & 0.2661 & 0.0325 & -0.3296 & 0.9371 & 0.1146 & 0.28 \\
\hline WET & V & 22 & 1 & 0.1852 & 0.2397 & 0.1505 & 0.5474 & 0.7086 & 0.4451 & 0.34 \\
\hline WET & W & 22 & 3 & -0.2606 & 0.0044 & -0.0903 & -0.9408 & 0.0259 & -0.3256 & 0.28 \\
\hline
\end{tabular}


MOX STS-2 U: $0.4361 \mathrm{~m} / \mathrm{Ts}^{2}$
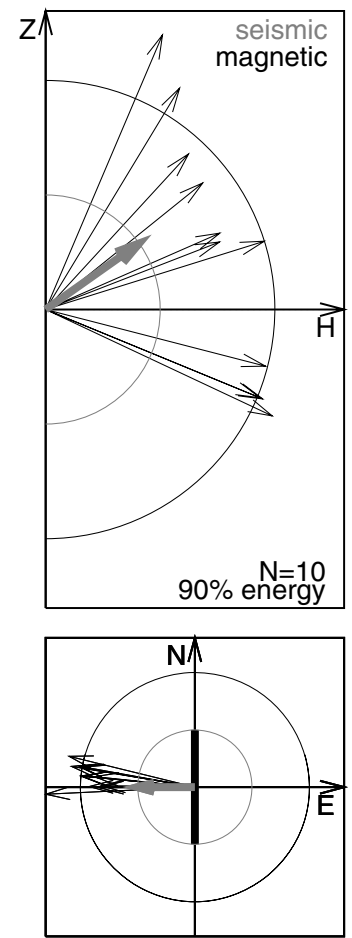

MOX STS-2 V: $0.4163 \mathrm{~m} / \mathrm{Ts}^{2}$
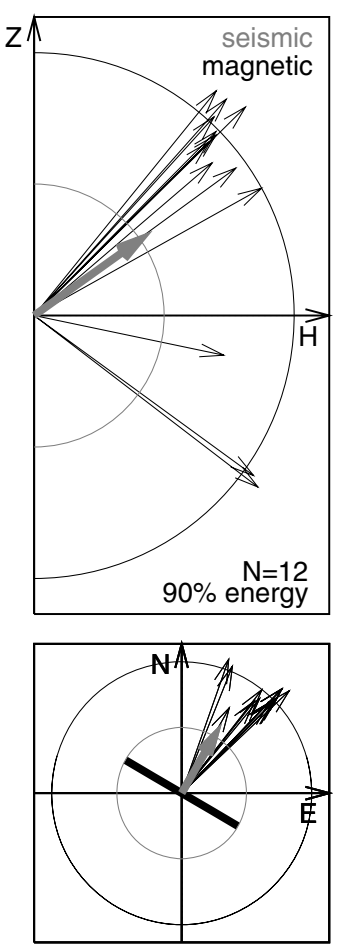

MOX STS-2 W: $0.4559 \mathrm{~m} / \mathrm{Ts}^{2}$
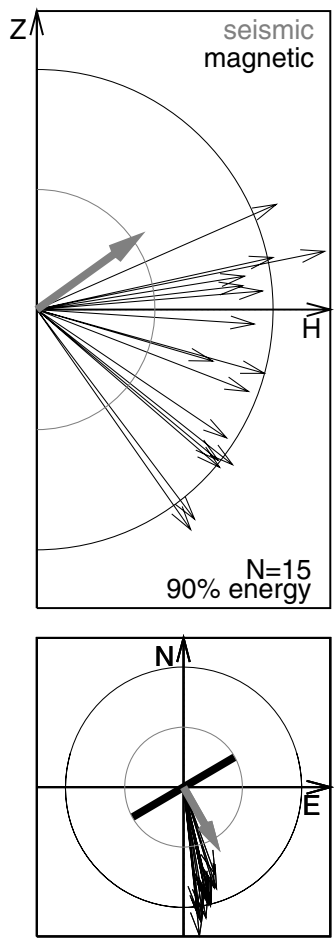

Figure 13. Sensitivities to the magnetic field vector for UVW-sensors of the STS-2 at MOX. See the caption of Fig. 11 for details. 


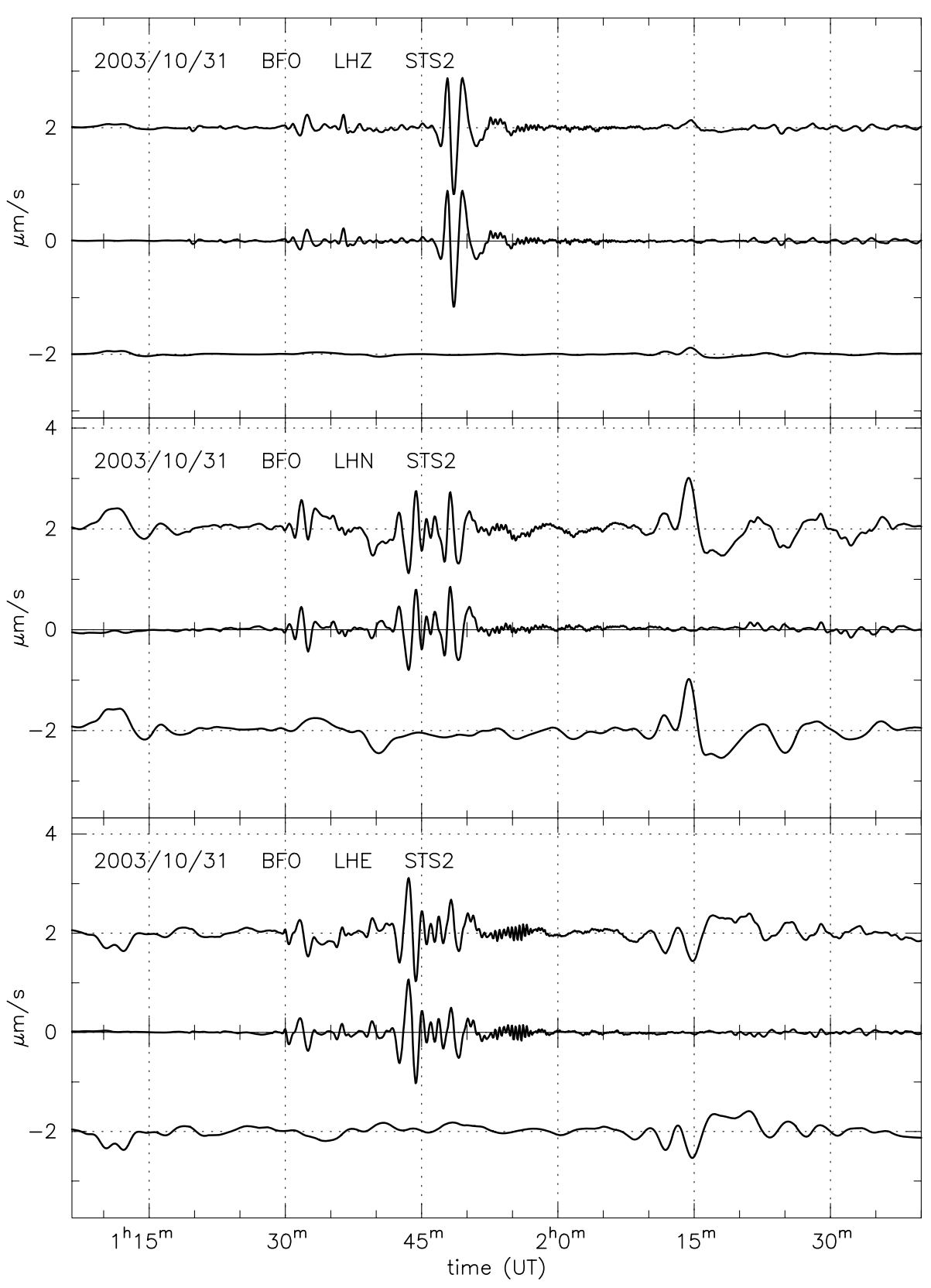

Figure 14. The coefficients given in Table 4 were used to improve the quality of the seismic recording by removing contributions due to the magnetic field. Results for the STS-2 at BFO are shown. The seismic waves from the Honshu-Earthquake on 2003 October $31\left(1: 06: 27 \mathrm{UT}, 37.84^{\circ} \mathrm{N}, 142.62^{\circ} \mathrm{E}, 10 \mathrm{~km}, \mathrm{M} 7.0\right)$ arrived during an ongoing magnetic storm. The wave train passed BFO after 1:20 UT. Seismic recordings are deteriorated mainly at periods of $200 \mathrm{~s}$ and longer due to the long period variations of the magnetic field. The three panels show the results for the Z-, N- and E-component of the seismometer, respectively. The three traces within each panel are vertically shifted by $2 \mu \mathrm{m} \mathrm{s}^{-1}$ each for better visibility. Top: seismic recording. Middle: signal after removal of magnetic field noise. Bottom: noise signal due to magnetic field that was removed from the top trace. The latter was predicted from the magnetic field recordings at BFO and the sensitivity values given in Table 4. 

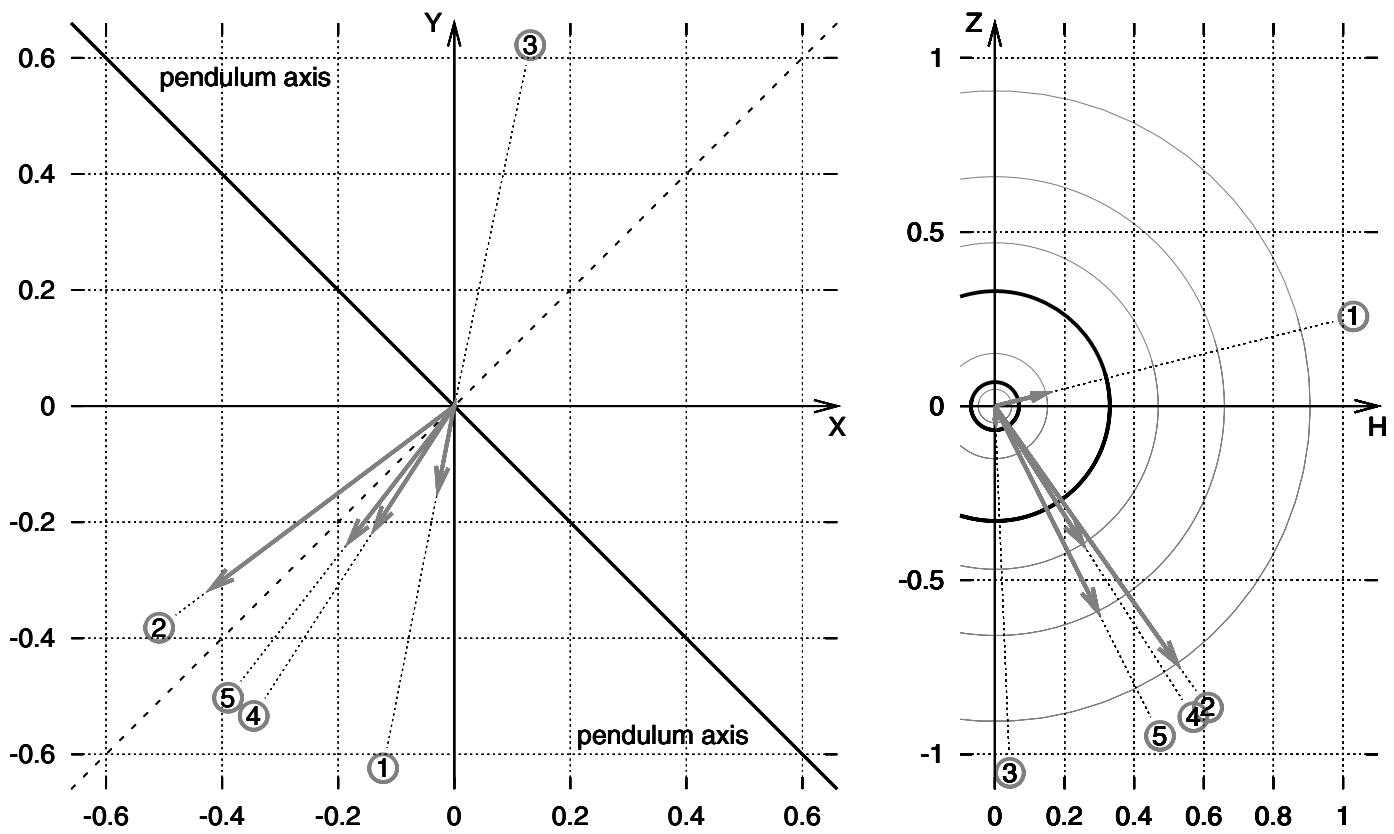

Figure 15. Sensitivity $\vec{s}\left(\mathrm{~m} \mathrm{~s}^{-2} \mathrm{~T}^{-1}\right)$ of the STS-1V (SN 1828, Table 1) in five different conditions. Left: projection on the horizontal plane. Right: vertical component over absolute horizontal component. (1) $S=0.15 \mathrm{~m} \mathrm{~s}^{-2} \mathrm{~T}^{-1}$ in the original state and (2) $S=0.91 \mathrm{~m} \mathrm{~s}^{-2} \mathrm{~T}^{-1}$ after a first attempt to demagnetize the instrument (both without Permalloy casing). (3) $S=0.05 \mathrm{~m} \mathrm{~s}^{-2} \mathrm{~T}^{-1}$ like (2) but with Permalloy casing. (4) $S=0.47 \mathrm{~m} \mathrm{~s}^{-2} \mathrm{~T}^{-1}$ after the second and (5) $S=0.66 \mathrm{~m} \mathrm{~s}^{-2} \mathrm{~T}^{-1}$ after a third attempt to demagnetize the instrument (both without Permalloy casing). The black diagonal in the left figure indicates the orientation of the seismometer's pendulum axis. The small black circle in the right Figure marks the sensitivity $\left(S=0.07 \mathrm{~m} \mathrm{~s}^{-2} \mathrm{~T}^{-1}\right)$ of the STS-1V (SN 28740 , Table 1) at BFO with Permalloy casing. The large black circle marks that $\left(S=0.33 \mathrm{~m} \mathrm{~s}^{-2} \mathrm{~T}^{-1}\right)$ of the UVW-components of the STS-2 (SN 19123$)$ at BFO (compare Table 4). 